\title{
Predicting PR EOS Binary Interaction Parameter Using Readily Available Molecular Properties
}

\author{
Agelia M. Abudour ${ }^{1}$ \\ Sayeed A. Mohammad ${ }^{1}$ \\ Robert L. Robinson, Jr. ${ }^{1}$ \\ ${ }^{*}$ Khaled A. M. Gasem ${ }^{1,2}$ \\ ${ }^{1}$ Oklahoma State University \\ School of Chemical Engineering \\ Stillwater, OK 74078 \\ ${ }^{2}$ University of Wyoming \\ Department of Chemical \& Petroleum Engineering \\ Laramie, WY 82071
}

*Author to whom all correspondence should be sent:

Email: gasem@uwyo.edu 


\section{Abstract}

The proper design, operation, simulation and optimization of numerous chemical processes require the knowledge of phase behavior of coexisting phases over wide ranges of pressure and temperature. A convenient method for describing equilibrium phase behavior is use of analytic equations of state. The most widely used equations of state (EOS) are the cubic van der Waals type equations such as the Soave-RedlichKwong (SRK) and Peng-Robinson (PR) EOS. These equations utilize one or two empirical binary interaction parameters (BIPs) for each binary pair in a mixture. These BIPs can have a significant effect on the predicted properties of mixtures and are generally required for accurate predictions.

In a recent work, we developed generalized models to estimate the BIPs in the PR EOS for non-ideal, low-pressure systems using a quantitative structure-property relationship (QSPR) modeling approach. In a departure from our earlier work, we present in this study a different modeling approach which utilizes only readily available molecular properties of the components involved in a mixture. This greatly simplifies application of our new models, since they do not require elaborate computational methods for generation of molecular descriptors.

To develop the present generalized model, a VLE database consisting of 1010 binary systems comprised of non-ideal, low-pressure binary systems as well as asymmetric, high-pressure binary systems was utilized. Using this database, the BIPs for the PR EOS were first determined by regressing the VLE experimental data for each system. Then, the BIPs were generalized in terms of molecular properties of components in a mixture. Results indicate that the generalized model provides bubble- 
point pressure predictions with an average absolute deviation (AAD) of $9 \%$ when compared with an AAD of $4.7 \%$ through direct regressions of the BIPs. Further, the model developed in this study was compared to our previous model by predicting bubble-point pressures of non-ideal, low-pressure binary systems. The predictions from the model developed in this study were comparable to our previous results $(9.2 \%$ compared to $8.3 \% A A D$ ), thus demonstrating the usefulness of the simpler approach presented in this work.

Keywords: Peng-Robinson equation of state, cubic equations of state, vapor-liquid equilibrium, generalized model, binary interaction parameters. 


\section{Introduction}

The prediction of vapor-liquid equilibrium of non-ideal mixtures over broad ranges of pressure and temperature is an important problem in chemical process design and operations. Although experiments provide accurate data at specific mixtures and phase conditions, such data are limited and may not fully meet the industrial needs for process design and development [1]. Therefore, a need exists for reliable predictive models to determine accurately the vapor-liquid equilibrium (VLE) for a wide variety of systems without the need for extensive experimentation.

Two methods are used in the majority of VLE calculations. While the first method employs an equation of state (EOS) model for both the liquid and vapor phase calculations, the second method uses the EOS model for the vapor phase and a liquid solution model for the liquid phase. In this work, an EOS model was used for both phases due to its capability in describing phase behavior at higher pressures as well as offering continuity in the critical region.

Although several equations of state of varying complexity are available, the cubic equations of state (CEOS) are used in the current work since these equations remain the most widely used EOS models in the chemical industry. Among the CEOS, two equations used routinely in the chemical industry are the Soave-Redlich-Kwong (SRK)[2] and Peng-Robinson (PR) [3]. Several mixing rules have been proposed for

applying the CEOS to mixtures [4-10]. However, the simplicity of the classical one-fluid mixing rules with one or two binary interaction parameters continues to make them attractive, particularly when the availability of such parameters in the literature is considered. In many applications, CEOS with these mixing rules can be used to 
represent systems within experimental precision[6]. Although other mixing rules that are more theoretically based, such as Wong-Sandler mixing rules [10], can be used to represent asymmetric mixtures [11], the multiple parameters associated with these mixing rules complicate developing parameter generalizations. Therefore, we elected to use the classical one-fluid mixing rules in this study for describing the vapor-liquid equilibrium of binary mixtures and for developing generalized models to predict the interaction parameter in the CEOS.

Several approaches, empirical as well as semi-empirical, have been presented in the literature to estimate the binary interaction parameters. These include simpler correlations using structural parameters [12-16]. Gasem et al. [12, 13] developed generalized correlations for the binary interaction parameters to represent the phase behavior of ethane $+n$-paraffin and $\mathrm{CO}_{2}+n$-paraffin systems. Gao et al. [14] developed generalized-parameter correlations for the conformal combining parameters $\left(\mathrm{N}_{\mathrm{ij}}\right)$ of the PR EOS for asymmetric binary mixtures involving methane, ethane, nitrogen, hydrogen, carbon monoxide and carbon dioxide in the n-paraffins $\left(\mathrm{C}_{4}-\mathrm{C}_{44}\right)$. Previously [15], we developed generalized correlations in terms of temperature for predicting the highpressure phase equilibria of mixtures of methane, nitrogen and carbon dioxide with water. Fateen et al. [16] developed correlations for the binary parameter, $C_{i j}$, for $P R$ EOS to predict vapor-liquid equilibria for systems containing hydrocarbons and related compounds. Although these correlations are easier to implement, they are limited by their range of applicability.

Jaubert and co-workers presented models based on the group-contribution method for the prediction of VLE phase behavior $[17,18]$. However, these models are 
limited for mixtures consisting of compounds for which functional groups are available. If the functional groups of interest are not available, experimental data are required to determine the interaction parameters. Lashkarbolooki et al. [19] developed a model for prediction of phase equilibria of binary systems containing carbon dioxide and hydrocarbons. Mohanty [20] developed a model to represent the phase behavior of binary systems including carbon dioxide-ethyl caproate, ethyl caprylate and ethyl caprate. Recently [15], we developed generalized models for the BIPs of the PR EOS using the quantitative structure-property relationship (QSPR) modeling methodology to predict the phase equilibria of non-ideal, low-pressure systems.

Our goal in this study was to develop generalized models that can be used without the need for extensive computation, availability of specific software and proprietary algorithms. Toward this end, we present in this study a generalized model for predicting the interaction parameter in the PR EOS using only readily available molecular properties of components in the mixture. Further, the generalized model is extended to include asymmetric, high-pressure systems in addition to non-ideal, lowpressure systems. The asymmetric systems include mixtures of light gases with high molecular weight solvents such as methane, ethane, nitrogen, hydrogen, carbon monoxide and carbon dioxide in $n$-paraffins $\left(\mathrm{C}_{4^{-}}-\mathrm{C}_{36}\right)$, cylcoparaffins and aromatic solvents. Thus, a generalized model capable of predicting phase behavior for both lowpressure and high-pressure binary systems was developed. To our knowledge, generalized models to estimate the BIPs of PR EOS in terms of such common molecular properties for diverse molecular structures in a large number of binary 
systems over wide ranges of pressure and temperature have not been presented previously in the literature.

The generalized model presented in this study constitutes a significant improvement over our previous work [15]. In particular, the model presented here

1. Uses only readily available molecular properties in the development of the generalized model.

2. Does not require the additional complexity of generating molecular descriptors using commercial software and/or proprietary algorithms.

3. Includes asymmetric, high-pressure binary systems in addition to non-ideal, low-pressure binary systems.

This study was structured to (a) test the capability of the PR EOS to describe the phase behavior of the systems studied using regressed BIPs (b) develop a generalized model that can predict the interaction parameter of the PR EOS for diverse systems and (c) evaluate the model predictions using an external test set not used in the model development.

The remaining sections are organized as follows: Section 2 presents the PR EOS model and the mixing rules used in this study, Section 3 presents details of the methodology used to develop the generalized model, Section 4 discusses the results for representing and predicting vapor-liquid equilibrium for low and high-pressure systems and finally, Section 5 presents the conclusions from this study.

\section{Peng-Robinson Equation of State}

Two cubic equations of state used widely in the chemical industry are the SoaveRedlich-Kwong (SRK) [2] and Peng-Robinson (PR) [3] equations. In this work, the PR 
EOS [3] with the $\alpha$ function by Gao, et al. [21] was used. To apply such an EoS to a mixture, mixing rules are necessary to calculate the values of the equation parameters of the mixture. The classical van der Waals one-fluid mixing rules were used [22].

\section{Generalization Methodology}

In a previous work [15], a quantitative structure-property relationship (QSPR) modeling methodology was used for generalizing the BIPs of the PR EOS. This approach uses quantum mechanics to define the structure of the molecule in terms of a series of molecular descriptors and correlates the desired property in terms of these descriptors. The method involves generating (a) two- and three-dimensional molecular structures, (b) minimizing the energy of the three-dimensional structures, (c) calculating descriptors for each molecule using the optimized geometry/structure of each molecule. These steps are generally accomplished using commercial software and/or proprietary algorithms. In the current work, the generalization methodology does not require any of these steps, since the model input comprises of only the common molecular properties.

The development of the generalized model for BIPs of the PR EOS presented in this study requires: (a) VLE database development, (b) PR EOS binary interaction parameter regression, (c) common molecular properties compilation, (e) property reduction procedures, (f) model development and (g) model validation.

The modeling process begins by compiling a representative binary VLE database. The binary interaction parameters of the PR EOS are then regressed for each binary system. Then, the molecular properties of components in each binary system are compiled. A total of 24 molecular properties for each component was included. The number of molecular properties is reduced to find the most significant 
molecular properties for predicting the BIPs. This is accomplished by a sequential regression algorithm that identifies only those properties that are useful in predicting the BIPs for these systems. This smaller set of properties is then used to develop an artificial neural network (ANN) model to predict BIPs. A detailed description for each of these different steps follows.

\subsection{Database Development}

The predictive capability of a generalized model depends strongly on the accuracy and quality of the experimental data used in the model development process. An experimental VLE database was compiled from available sources covering several functional groups. The VLE database consisted of a total of 1010 binary systems including both low-pressure and high-pressure binary systems. Details of this binary VLE experimental database along with the temperature, pressure and composition ranges for each binary system can be found in Table S1 of the Supplementary Material available with the web edition of this paper.

\subsubsection{Low-pressure Systems Database}

The low-pressure VLE database consists of a total of 913 binary systems formed from various combinations of 138 different compounds totaling over 33,000 data points [23]. This database is comprised of systems of aliphatic and aromatic hydrocarbons, water, alcohols, ethers, sulfides and nitrile compounds. This experimental low-pressure VLE data were taken from DECHEMA [24] and NIST-TDE [25]. The range of pressures for the database was about 1-58 bar and the range of temperatures was about 182-554 $\mathrm{K}$.

\subsubsection{High-pressure Systems Database}


The high-pressure VLE database consists of asymmetric binary systems involving light gas solutes (methane, ethane, nitrogen, hydrogen, carbon monoxide and carbon dioxide) and hydrocarbon solvents (n-paraffins $\left(\mathrm{C}_{4}-\mathrm{C}_{36}\right)$, cylcoparaffins and aromatic). These binary systems are encountered in several important industries such as enhanced oil recovery, supercritical extraction and Fisher-Tropsch syntheses. This database consists of a total of 97 binary systems formed from various combinations of 37 different compounds totaling about 4000 data points. The values of the critical temperature $\left(T_{c}\right)$, critical pressure $\left(P_{c}\right)$ and acentric factor $(\omega)$ for n-paraffins $\left(C_{1}-C_{20}\right)$, cylcoparaffins and aromatics are taken from Reid et al.[26] For n-paraffins heavier than $\mathrm{C}_{20}$, the values of the input variables were estimated from the asymptotic behavior correlation of Gasem, et al. [13].

\subsection{Binary Interaction Parameter (BIP) Regressions}

The PR EOS binary interaction parameters for the 1010 binary systems were obtained by regressing the experimental data for each system. To determine the optimum values of the BIPS in the PR EOS model, regression analyses used a nonlinear regression procedure based on the Marquardt method [27, 28]. An equilibrium algorithm, GEOS [29], was used to determine the bubble-point pressures using the following familiar equilibrium relation:

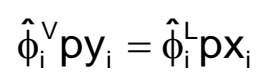

where $x_{i}$ and $y_{i}$ are the liquid and vapor mole fractions of any component $i, \hat{\phi}_{i}^{v}$ and $\hat{\phi}_{i}^{L}$ are the component fugacity coefficients in the vapor and liquid phase, respectively. 
Since much of the available data is in T-p-x form, only the liquid-phase compositions were used in the evaluations. The following objective function was used in the regressions.

$$
\mathrm{OF}=\sum_{\mathrm{i}=1}^{\mathrm{NDP}}\left(\frac{\boldsymbol{p}_{\text {cal }}-\mathrm{p}_{\text {exp }}}{\boldsymbol{p}_{\text {exp }}}\right)_{i}^{2}
$$

where NDP is the number of data points, $p_{\text {exp }}$ and $p_{\text {cal }}$ are the experimental and calculated bubble-point pressures at specified values of $T, x$.

\subsection{Generalized Model Input}

A total of 24 molecular properties for each component was compiled. Table 1 lists all of the properties considered in this study. Of the 24 properties, 23 properties were taken from DIPPR [30] and octanol-water partition coefficient values were taken from PhysProp database [31]. These property values were used as input in the development of the generalized model. For each binary system, the input molecular property set was prepared by calculating the absolute differences in the component molecular properties [23]. The absolute differences were used to ensure that the generalized model remains internally consistent. If a hypothetical binary system consisting of identical compounds is used, the generalized model will correctly predict zero values for the BIPs (if $i=j, C_{i j}=$ $\left.D_{i j}=0\right)$. Further, this method also ensures that the generalized model will be applicable even if the components of a binary pair are interchanged $(i, j=j, i)$.

\subsection{Property Reduction}

As mentioned earlier, a total of 24 molecular properties was compiled for each component. However, most of these molecular properties have negligible influence in describing a specific property of a component. Therefore, Reduction methodologies 
were then used to reduce the number of molecular properties by finding those that are most significant for describing a given property of interest.

In the current work, a sequential regression analysis [32] was used to identify the most significant descriptors for describing the BIPs, $C_{i j}$. The molecular properties identified in this step were then used to construct an artificial neural network (ANN) model. A detailed discussion on our reduction methodology can be found in a previous work [32].

\subsection{Generalized Model Development}

In the ANN model development process, the input dataset was divided into training, validation, internal test and external test sets that contained $50 \%, 18 \%, 10 \%$, $22 \%$ of the data, respectively. The data was divided based on the functional-group interactions to ensure that all four data sets contained adequate representation of each of the functional-group interactions present in the database. The ANN model used the back-propagation algorithm for training the multi-layer perceptron network [33]. An early-stopping method $[34,35]$ was used to prevent over-fitting by the model. During initial phases of the ANN training, the errors in both the training and validation sets decrease; however, when the ANNs begins to over-fit the data, the error for the validation set increases. The ANN model training was stopped after a preset number of iterations in which the error on the validation set increased continuously, and the ANN parameters at the minimum of the validation set error were retained. Further, to ensure optimal ANN training and avoid local minima, multiple randomizations of the data and initializations of the ANN parameters (weights and biases) were used [36]. The NguyenWidrow [37] algorithm was used to initialize the network weights and biases and 
parameters were updated using a Levenberg-Marquardt optimization technique [33]. Additional details of the ANN algorithm used in this study have been presented in an earlier work [32].

\subsection{Creating ANN Ensembles}

Artificial neural network (ANN) models can be unstable and their predictive performance is dependent strongly on the training data and training parameters. Therefore, a single outlier in the training data could have a disproportional effect on the generalization capability of the final model. To prevent this, an ensemble of ANNs was utilized, where the predictions of different ANNs were averaged to yield the final predictions [38-40]. In this study, the final ensemble model consisted of averaging 20 ANNs, each having the same descriptors as inputs but with different network architecture and weights.

\subsection{Model Validation}

The generalized model was validated by employing an external test set of compounds not used in the model development, as emphasized by Tropsha et al. [41]. The performance of the model on this external dataset indicates the generalization capability of the final model.

\subsection{Model Evaluation}

The VLE database utilized in this work consisted of 1010 binary systems formed from 913 low-pressure systems and 97 high-pressure systems. Therefore, three separate models were constructed as listed in Table 2. Specifically, Model 1 is based on all 1010 binary systems in the database, whereas Model 2 included only the non-ideal, 
low-pressure systems (913 systems). Model 3 is based on only the asymmetric, highpressure systems (97 systems).

In the following discussion, the model results are presented in terms of the rootmean-squared error (RMSE), bias and average absolute percent deviations (\%AAD).

$$
\begin{aligned}
& \text { RMSE }=\left(\frac{\sum_{i=1}^{N D P}\left(p_{\text {cal }}-p_{\text {exp }}\right)^{2}}{N D P}\right)^{1 / 2} \\
& \text { bias }=\frac{\sum_{i=1}^{N D P}\left(p_{\text {cal }}-p_{\text {exp }}\right)}{N D P} \\
& \% A A D=\frac{100}{N D P} \sum_{i=1}^{N D P}\left|\frac{p_{\text {cal }}-p_{\text {exp }}}{p_{\text {exp }}}\right|_{i}
\end{aligned}
$$

where NDP is the number of data points, $p_{\text {exp }}$ and $p_{\text {cal }}$ are the experimental and calculated bubble-point pressures, respectively.

\section{Results and Discussion}

\subsection{Single Parameter, $C_{\mathrm{ij}}$, Representations}

The use of a single interaction parameter, $C_{i j}$, specific to each binary system is a routine industrial practice and was used in this study. Table 3 presents the regression results for the three models listed in Table 2. As shown in Table 3, the average absolute deviation (AAD) ranged from $3 \%$ to $4.7 \%$ for the three models. The inclusion of a second interaction parameter in the PR EOS was also investigated in an earlier work [15] and provided only marginal improvements over the results presented here. Therefore, the inclusion of a second interaction parameter, $D_{\mathrm{i} j}$, for each binary system was not considered in the current work. Detailed information on bubble-point pressure 
representations as well as values of the optimized BIPs $\left(C_{i j}\right)$ for the complete database is provided in Table S1 of the Supplementary Material available with the web edition of this paper.

\subsection{Generalized Model Predictions}

The regressed BIPs $\left(C_{i j}\right)$ obtained from PR EOS were used as targets in the development of the generalized models. As mentioned above, three separate models were developed and a sequential regression analysis [32] was used to identify the most significant molecular properties for describing the BIPs, $C_{i j}$, separately for each model. Table 4 lists the 15 molecular properties that were identified by the reduction algorithm as significant in predicting the BIPs for the systems included in Model 1 (entire data base). The table lists the properties in descending order of statistical significance in predicting the BIPs. For the systems included in Model 2 and 3, the reduction procedure identified a total of 10 and 7 molecular properties, respectively, as significant in predicting the BIPs. Tables 5 and 6 list the molecular properties used in estimating the parameter $\mathrm{C}_{\mathrm{ij}}$ in Models 2 and 3 , respectively.

Figure 1 compares the regressed $C_{i j}$ values from the PR EOS with the predicted $\mathrm{C}_{\mathrm{ij}}$ values from Generalized Model 1 in the training, validation and external test sets. The figure indicates that the generalized model predictions are in good agreement with the parameter values regressed directly from the PR EOS. The residuals for $\mathrm{C}_{\mathrm{ij}}$ obtained in Model 1 are plotted in Figure 2, which demonstrates that the residuals are distributed uniformly and do not appear to have any large bias. Figures 3 and 5 compare the

regressed $C_{i j}$ values from the PR EOS with the predicted $C_{i j}$ values from the Generalized Models 2 and 3, respectively, in the training, validation and external test 
sets. The corresponding residuals for $C_{i j}$ are shown in Figures 4 and 6 , respectively, for Models 2 and 3 , respectively.

Table 7 presents the summary results for the bubble-point pressure predictions using the generalized models. The table provides the results for all systems (Model 1) in the database, for non-ideal, low-pressure systems (Model 2) and for asymmetric, highpressure systems (Model 3). The results are classified into training, validation, internal test and external test sets. The generalized model predictions contain higher error than direct model regressions, as expected. Table 7 indicates that the external and internal test set predictions were comparable to the overall predictions, which demonstrates the capability for generalized predictions for systems not used in the model development.

Figures 7-11 illustrate the generalized model predictions for equilibrium phase compositions of methyl cyclohexane + ethyl tertiary butyl ether, n-octane + ethylbenzene, methyl acetate + carbon disulfide, and dimethyl disulfide + methyl mercaptan systems, respectively. The figures include a comparison between the PR EOS model representations and predictions from the Generalized Models 1 and 2. As evident from the figures, the generalized models provide predictions similar to the direct regressions. Further, the predictions from the generalized models are in good agreement with the experimental composition values for each system at the selected temperatures and pressures. This highlights the capabilities of the generalized models for predicting various types of phase behavior ranging from nearly ideal to highly nonideal systems.

Figures 12-18 show the generalized model predictions for equilibrium phase compositions of carbon dioxide + propane, methane + decane, ethane + pentane, 
nitrogen + methylcyclohexane, carbon dioxide + hextriacontane, and methane + eicosane. The figures include a comparison between the PR EOS model regressions and predictions from the Generalized Models 1 and 3 . As evident from these figures, the generalized models provide reasonably accurate predictions of phase compositions for these systems.

\subsection{Comparison with Previous Work}

The results from this study were compared with a previous work[15] that included a molecular structure-based model for predicting the BIPs. Table 8 presents a comparison of predictions between Generalized Model 2 from this study and the PRQSPR model from an earlier work. The model developed in this study provided comparable predictions to those of the PR-QSPR model. Specifically, the predictions yielded $9.2 \%$ and $8.3 \%$ AAD for Generalized Model 2 and the PR-QSPR model, respectively. Considering that the current model includes a significant simplification over the previous PR-QSPR modeling approach (i.e., 10 molecular properties as input compared to 30 molecular descriptors in the PR-QSPR model), the predictions from the Generalized Model 2 illustrate the capability of the generalized model developed in this study.

We note here that the current work has focused exclusively on developing generalized BIPs for predicting vapor-liquid equilibrium, and therefore the quality of EOS predictions for other types of phase equilibria such as liquid-liquid equilibrium has not been considered in this study. 


\section{Conclusions}

The PR EOS was employed to model the vapor-liquid equilibrium of 1010 binary systems including non-ideal, low-pressure systems as well as asymmetric, highpressure systems. Generalized models were developed for predicting the interaction parameter, $\mathrm{C}_{\mathrm{ij}}$, using readily available molecular properties of components in a mixture. Results indicate that the generalized models are capable of predicting bubble-point pressures with an overall average absolute deviation of $9 \%$. This compared with an average absolute deviation of $4.7 \%$ obtained from direct regressions of the interaction parameter. Further, the generalized model predictions were compared with our earlier results from a molecular-structure-based model. The predictions from the model developed in this work were similar in accuracy, and the current model also contained a significant simplification in the complexity of the modeling process. Thus, the generalized model developed in this study represents a useful alternative for predicting vapor-liquid equilibrium for both low-pressure and high-pressure systems.

\section{Acknowledgment}

We gratefully acknowledge the financial support received from the U.S. Department of Energy and the Regional Partnership to Secure Energy for America (RPSEA). 


\section{References}

[1] S. Zeck, D. Wolf, Requirements of thermodynamic data in the chemical industry, Fluid Phase Equilibria, 82 (1993) 27-38.

[2] G. Soave, Equilibrium constants from a modified Redlich-Kwong equation of state, Chemical Engineering Science, 27 (1972) 1197-1203.

[3] D.Y. Peng, D.B. Robinson, A new two-constant equation of state, Industrial \& Engineering Chemistry Fundamentals, 15 (1976) 59-64.

[4] P.M. Mathias, H.C. Klotz, J.M. Prausnitz, Equation-of-state mixing rules for multicomponent mixtures: the problem of invariance, Fluid Phase Equilibria, 67 (1991) 31-44.

[5] J. Schwartzentruber, H. Renon, Equations of state: how to reconcile flexible mixing rules, the virial coefficient constraint and the "Michelsen-Kistenmacher syndrome" for multicomponent systems, Fluid Phase Equilibria, 67 (1991) 99-110.

[6] S.K. Shibata, S.I. Sandler, Critical evaluation of equation of state mixing rules for the prediction of high-pressure phase equilibria, Industrial and Engineering Chemistry Research, 28 (1989) 1893-1898.

[7] P.T. Eubank, G.-S. Shyu, N.S.M. Hanif, New procedures for application of the WongSandler mixing rules to the prediction of vapor-liquid equilibria, Industrial and Engineering Chemistry Research, 34 (1995) 314-323.

[8] H. Orbey, S.I. Sandler, Reformulation of Wong-Sandler mixing rule for cubic equations of state, AIChE Journal, 41 (1995) 683-690.

[9] C.H. Twu, J.E. Coon, J.R. Cunningham, A new generalized alpha function for a cubic equation of state Part 1. Peng-Robinson equation, Fluid Phase Equilibria, 105 (1995) 49-59.

[10] D.S.H. Wong, S.I. Sandler, A theoretically correct mixing rule for cubic equations of state, AIChE Journal, 38 (1992) 671-680.

[11] N. Trivedi, M. S. Thesis, in, Oklahoma State University, Stillwater, OK, 1996.

[12] K.A.M. Gasem, C.H. Ross, R.L. Robinson, Prediction of ethane and $\mathrm{CO}_{2}$ solubilities in heavy norma paraffins using generalized-parameter Soave and Peng-Robinson equations of state, The Canadian Journal of Chemical Engineering, 71 (1993) 805-816.

[13] K.A.M. Gasem, Binary vapor-liquid phase equilibrium for carbon dioxide + heavy normal paraffins (interaction parameters, density predictions, pure hydrocarbon properties), in, Oklahoma State University, United States -- Oklahoma, 1986. 
[14] W. Gao, R.L. Robinson Jr, K.A.M. Gasem, Alternate equation of state combining rules and interaction parameter generalizations for asymmetric mixtures, Fluid Phase Equilibria, 213 (2003) 19-37.

[15] A.M. Abudour, S.A. Mohammad, R.L. Robinson Jr, K.A.M. Gasem, Generalized binary interaction parameters for the Peng-Robinson equation of state, Fluid Phase Equilibria, 383 (2014) 156-173.

[16] S.-E.K. Fateen, M.M. Khalil, A.O. Elnabawy, Semi-empirical correlation for binary interaction parameters of the Peng-Robinson equation of state with the van der Waals mixing rules for the prediction of high-pressure vapor-liquid equilibrium, Journal of Advanced Research, 4 (2013) 137-145.

[17] J.-N. Jaubert, F. Mutelet, VLE predictions with the Peng-Robinson equation of state and temperature dependent kij calculated through a group contribution method, Fluid Phase Equilibria, 224 (2004) 285-304.

[18] J.-N. Jaubert, S. Vitu, F. Mutelet, J.-P. Corriou, Extension of the PPR78 model (predictive 1978, Peng-Robinson EOS with temperature dependent kij calculated through a group contribution method) to systems containing aromatic compounds, Fluid Phase Equilibria, 237 (2005) 193-211.

[19] M. Lashkarbolooki, Z.S. Shafipour, A.Z. Hezave, H. Farmani, Use of artificial neural networks for prediction of phase equilibria in the binary system containing carbon dioxide, The Journal of Supercritical Fluids, 75 (2013) 144-151.

[20] S. Mohanty, Estimation of vapour liquid equilibria of binary systems, carbon dioxide-ethyl caproate, ethyl caprylate and ethyl caprate using artificial neural networks, Fluid Phase Equilibria, 235 (2005) 92-98.

[21] W. Gao, R.L. Robinson Jr, K.A.M. Gasem, Improved correlations for heavy nparaffin physical properties, Fluid Phase Equilibria, 179 (2001) 207-216.

[22] J.M. Prausnitz, R.N. Lichtenthaler, E.G. Azevedo, Molecular Thermodynamics of Fluid-Phase Equilibria, 3rd ed., Prentice-Hall, New Jersey, 1999.

[23] S. Gebreyohannes, B.J. Neely, K.A.M. Gasem, Generalized Interaction Parameter for the Modified Nonrandom Two-Liquid (NRTL) Activity Coefficient Model, Industrial \& Engineering Chemistry Research, 53 (2014) 20247-20257.

[24] U.O. J. Gmehling, W. Arlt,, Vapor-liquid equilibrium data collection, chemistry data series, in: DECHEMA (Ed.), Frankfurt, Germany, 1977 - 2001.

[25] NIST standard reference database 103b thermodata engine, in: NIST-TDE (Ed.), 2012.

[26] R.C. Reid, J.M. Prausnitz, B.E. Poling, The Properties of Gases and Liquids, fourth ed., McGraw-Hill, 1987. 
[27] D.W. Marquardt, An algorithm for least-squares estimation of nonlinear parameters, Journal of the Society for Industrial and Applied Mathematics, 11 (1963) 431-441.

[28] L.W. Jackson, A Comparison of Selected Gradient Methods for Solving Nonlinear Least Squares Problem, in, Oklahoma State University, Stillwater, OK, 1978.

[29] K.A.M. Gasem, GEOS, in, Oklahoma State University, Stillwater, OK, 1988-1999.

[30] Physical and thermodynamic properties of pure chemicals, DIPPR Project 801, (2011).

[31] Physical/Chemical Property Database (Physprop), Syracuse Research Corporation, (1994).

[32] S. Golla, S. Madihally, R.L. Robinson Jr, K.A.M. Gasem, Quantitative structureproperty relationship modeling of skin sensitization: A quantitative prediction, Toxicology in Vitro, 23 (2009) 454-465.

[33] H. Demuth, M. Beale, M. Hagan, Neural Network Toolbox, in, MathWorks, Inc., 2010.

[34] C.S. Rich, L.; Lee, G., Overfitting in neural nets: backpropagation, conjugate gradient, and early stopping., in: Advances in Neural Information Processing Systems 13: Proceedings of the 2000 Conference, 2001.

[35] L. Prechelt, Automatic early stopping using cross validation: quantifying the criteria, Neural Networks, 11 (1998) 761-767.

[36] M.S. lyer, R.R. Rhinehart, A method to determine the required number of neuralnetwork training repetitions, Neural Networks, IEEE Transactions on, 10 (1999) 427432.

[37] D. Nguyen, B. Widrow, Improving the learning speed of 2-layer neural networks by choosing initial values of the adaptive weights, in: Proceedings of the International Joint Conference on Neural Networks, 1990, pp. 21-26.

[38] K.M. Yerramsetty, Quantitative structure-property relationship modeling \& computer-aided molecular designimprovements \& applications /by Krishna M. Yerramsetty, in: Chemical Engineering, Oklahoma State University, Stillwater, 2012, pp. 290.

[39] D.K. Agrafiotis, W. Cedeño, V.S. Lobanov, On the use of neural network ensembles in QSAR and QSPR, Journal of Chemical Information and Computer Sciences, 42 (2002) 903-911.

[40] C. Merkwirth, H. Mauser, T. Schulz-Gasch, O. Roche, M. Stahl, T. Lengauer, Ensemble methods for classification in cheminformatics, Journal of Chemical Information and Computer Sciences, 44 (2004) 1971-1978. 
[41] A. Tropsha, P. Gramatica, V.K. Gombar, The Importance of Being Earnest: Validation is the Absolute Essential for Successful Application and Interpretation of QSPR Models, QSAR \& Combinatorial Science, 22 (2003) 69-77.

[42] S. Gebreyohannes, B.J. Neely, K.A.M. Gasem, Generalized Nonrandom TwoLiquid (NRTL) Interaction Model Parameters for Predicting Liquid-Liquid Equilibrium Behavior, Industrial \& Engineering Chemistry Research, 53 (2014) 12445-12454. 


\section{Table 1. Molecular Properties Considered in this Study}

\begin{tabular}{|l|l|l|}
\hline No. & $\begin{array}{l}\text { Property } \\
\text { Symbol }\end{array}$ & Property \\
\hline 1 & P $_{\text {C }}$ & Critical Pressure $(\mathrm{Pa})$ \\
\hline 2 & Kow & Log P (octanol-water partition coefficient) \\
\hline 3 & ACEN & Acentric Factor \\
\hline 4 & DM & Dipole Moment (D) \\
\hline 5 & LVOL & Liquid Molar Volume at a reference temperature and pressure $\left(\mathrm{m}^{3} / \mathrm{kmol}\right)$ \\
\hline 6 & SOLP & Solubility Parameter at a reference temperature and pressure $\left(\left(\mathrm{J} / \mathrm{m}^{3}\right)^{1 / 2}\right)$ \\
\hline 7 & V & Critical Volume $\left(\mathrm{m}^{3} / \mathrm{kmol}\right)$ \\
\hline 8 & VDWV & van der Waals Reduced Volume $\left(\mathrm{m}^{3} / \mathrm{kmol}\right)$ \\
\hline 9 & HSTD & Standard State Enthalpy of Formation at $298.15 \mathrm{~K}$ and $1 \mathrm{bar}(\mathrm{J} / \mathrm{kmol})$ \\
\hline 10 & TC & Critical Temperature $(\mathrm{K})$ \\
\hline 11 & MP & Melting Point at 1 atm $(\mathrm{K})$ \\
\hline 12 & VDWA & van der Waals Area $\left(\mathrm{m}^{3} / \mathrm{kmol}\right)$ \\
\hline 13 & TPP & Triple Point Pressure $(P a)$ \\
\hline 14 & HFOR & Enthalpy of Formation for Ideal Gas at $298.15 \mathrm{~K}(\mathrm{~J} / \mathrm{kmol})$ \\
\hline 15 & TPT & Triple Point Temperature $(\mathrm{K})$ \\
\hline 16 & MW & Molecular Weight $(\mathrm{kg} / \mathrm{kmol})$ \\
\hline 17 & ENT & Absolute Entropy of Ideal Gas at $298.15 \mathrm{~K}$ and $1 \mathrm{bar}(\mathrm{J} /(\mathrm{kmol} \cdot \mathrm{K}))$ \\
\hline 18 & NBP & Normal Boiling Point $(\mathrm{K})$ \\
\hline 19 & RI & Refractive Index \\
\hline 20 & SSTD & Standard State Absolute Entropy at $298.15 \mathrm{~K}$ and $1 \mathrm{bar}(\mathrm{J} /(\mathrm{kmol} \cdot \mathrm{K}))$ \\
\hline 21 & ZC & Critical Compressibility Factor \\
\hline 22 & GSTD & Standard State Gibbs Energy of Formation at $298.15 \mathrm{~K} \mathrm{\&} 1 \mathrm{bar}(\mathrm{J} / \mathrm{kmol})$ \\
\hline 23 & GFOR & Gibbs Energy of Formation for Ideal Gas at $298.15 \mathrm{~K} \mathrm{\&} 1 \mathrm{bar}(\mathrm{J} / \mathrm{kmol})$ \\
\hline 24 & RG & Radius of Gyration $(M)$ \\
\hline
\end{tabular}

${ }^{*} \mathrm{~K}_{\mathrm{ow}}$ values are from the PhysProp database [31] and all other properties are from DIPPR [30] 
Table 2. Generalized Models Developed in this Study and Used for PR EOS Evaluations

\begin{tabular}{|c|c|l|}
\hline Model & $\begin{array}{c}\text { No. of } \\
\text { systems }\end{array}$ & Description \\
\hline 1. & 1010 & $\begin{array}{l}\text { All 1010 binary systems (non-ideal low pressure and asymmetric } \\
\text { high pressure) were included in the modeling process }\end{array}$ \\
\hline 2. & 913 & $\begin{array}{l}\text { Non-ideal low pressure systems were included in the modeling } \\
\text { process }\end{array}$ \\
\hline 3. & 97 & $\begin{array}{l}\text { Asymmetric high pressure systems were included in the modeling } \\
\text { process }\end{array}$ \\
\hline
\end{tabular}

Table 3. Summary Results for PR EOS Regressions of Bubble-point Pressure for Low and High-pressure Binary Systems

\begin{tabular}{|c|l|c|c|c|c|c|}
\hline \multicolumn{7}{|c|}{ Bubble-point Pressure, bar } \\
\hline \multirow{2}{*}{ Model } & \multicolumn{1}{|c|}{ Data set } & No. Sys. & NDP & RMSE & Bias & $\%$ AAD \\
\hline $\mathbf{1}$ & All Data & 1010 & 37027 & 2.3 & 0.01 & 4.7 \\
\hline $\mathbf{2}$ & Non-ideal, low-pressure systems & 913 & 33139 & 2.0 & -0.01 & 4.8 \\
\hline $\mathbf{3}$ & Asymmetric, high-pressure systems & 97 & 3888 & 4.4 & 0.20 & 3.0 \\
\hline
\end{tabular}


Table 4. Molecular Properties Used for Predicting $C_{i j}$ in Model 1

\begin{tabular}{|l|l|l|}
\hline No. & $\begin{array}{l}\text { Property } \\
\text { Symbol }\end{array}$ & Property \\
\hline 1 & $\mathrm{P}_{\mathrm{C}}$ & Critical Pressure $(\mathrm{Pa})$ \\
\hline 2 & $\mathrm{~T}_{\mathrm{C}}$ & Critical Temperature $(\mathrm{K})$ \\
\hline 3 & Kow & Log P (octanol-water partition coefficient) \\
\hline 4 & NBP & Normal Boiling Point $(\mathrm{K})$ \\
\hline 5 & ACEN & Acentric Factor \\
\hline 6 & TPP & Triple Point Pressure $(\mathrm{Pa})$ \\
\hline 7 & DM & Dipole Moment $(\mathrm{D})$ \\
\hline 8 & RI & Refractive Index \\
\hline 9 & SOLP & Solubility Parameter at a reference temperature and pressure $\left(\left(\mathrm{J} / \mathrm{m}^{3}\right)^{1 / 2}\right)$ \\
\hline 10 & LVOL & Liquid Molar Volume at a reference temperature and pressure $\left(\mathrm{m}^{3} / \mathrm{kmol}\right)$ \\
\hline 11 & HSTD & Standard State Enthalpy of Formation at $298.15 \mathrm{~K}$ and $1 \mathrm{bar}(\mathrm{J} / \mathrm{kmol})$ \\
\hline 12 & $\mathrm{~V}_{\mathrm{C}}$ & Critical Volume $\left(\mathrm{m}^{3} / \mathrm{kmol}\right)$ \\
\hline 13 & TPT & Triple Point Temperature $(\mathrm{K})$ \\
\hline 14 & MP & Melting Point at 1 atm $(\mathrm{K})$ \\
\hline 15 & MW & Molecular Weight $(\mathrm{kg} / \mathrm{kmol})$ \\
\hline
\end{tabular}

Table 5. Molecular Properties Used for Predicting $C_{i j}$ in Model 2

\begin{tabular}{|l|l|l|}
\hline No. & $\begin{array}{l}\text { Property } \\
\text { Symbol }\end{array}$ & Property \\
\hline 1 & $\mathrm{P}_{\mathrm{C}}$ & Critical Pressure $(\mathrm{Pa})$ \\
\hline 2 & Kow & Log P (octanol-water partition coefficient) \\
\hline 3 & ACEN & Acentric Factor \\
\hline 4 & DM & Dipole Moment $(\mathrm{D})$ \\
\hline 5 & SOLP & Solubility Parameter at a reference temperature and pressure $\left(\left(\mathrm{J} / \mathrm{m}^{3}\right)^{1 / 2}\right)$ \\
\hline 6 & ENT & Absolute Entropy of Ideal Gas at $298.15 \mathrm{~K}$ and 1 bar $(\mathrm{J} /(\mathrm{kmol} \cdot \mathrm{K}))$ \\
\hline 7 & LVOL & Liquid Molar Volume at a reference temperature and pressure $\left(\mathrm{m}^{3} / \mathrm{kmol}\right)$ \\
\hline 8 & $V_{C}$ & Critical Volume $\left(\mathrm{m}^{3} / \mathrm{kmol}\right)$ \\
\hline 9 & VDWV & van der Waals Reduced Volume $\left(\mathrm{m}^{3} / \mathrm{kmol}\right)$ \\
\hline 10 & MP & Melting Point at 1 atm $(\mathrm{K})$ \\
\hline
\end{tabular}


Table 6. Molecular Properties Used for Predicting $C_{i j}$ in Model 3

\begin{tabular}{|l|l|l|}
\hline No. & $\begin{array}{l}\text { Property } \\
\text { Symbol }\end{array}$ & Property \\
\hline 1 & SOLP & Solubility Parameter at a reference temperature and pressure $\left(\left(\mathrm{J} / \mathrm{m}^{3}\right)^{1 / 2}\right)$ \\
\hline 2 & $\mathrm{~T}_{\mathrm{C}}$ & Critical Temperature $(\mathrm{K})$ \\
\hline 3 & MW & Molecular Weight $(\mathrm{kg} / \mathrm{kmol})$ \\
\hline 4 & MP & Melting Point at $1 \mathrm{~atm}(\mathrm{~K})$ \\
\hline 5 & Kow & Log P (octanol-water partition coefficient) \\
\hline 6 & HSTD & Standard State Enthalpy of Formation at $298.15 \mathrm{~K}$ and $1 \mathrm{bar}(\mathrm{J} / \mathrm{kmol})$ \\
\hline 7 & RI & Refractive Index \\
\hline
\end{tabular}


Table 7. Summary Results for Bubble-point Pressure Predictions Using the Generalized Models

\begin{tabular}{|l|c|c|c|c|c|}
\hline \multicolumn{7}{|c|}{ Bubble Point Pressure, bar } \\
\hline Data set & No. sys. & NDP & RMSE & Bias & \%AAD \\
\hline \multicolumn{7}{|c|}{ Model 1 (all systems) } \\
\hline Training Set & 508 & 18514 & 5.2 & 0.2 & 7.7 \\
\hline Validation Set & 182 & 6665 & 3.0 & 0.1 & 8.9 \\
\hline Internal Test Set & 107 & 3703 & 9.7 & 0.4 & 9.7 \\
\hline External Test Set & 213 & 8146 & 3.2 & 0.1 & 10.1 \\
\hline All data & $\mathbf{1 0 1 0}$ & $\mathbf{3 7 0 2 7}$ & $\mathbf{4 . 4}$ & $\mathbf{0 . 1}$ & $\mathbf{9 . 0}$ \\
\hline \multicolumn{7}{|c|}{ Model 2 (non-ideal, low-pressure systems) } \\
\hline Training Set & 459 & 16570 & 0.3 & -0.02 & 8.4 \\
\hline Validation Set & 166 & 5965 & 0.2 & -0.03 & 9.5 \\
\hline Internal Test Set & 101 & 3314 & 0.1 & -0.01 & 9.6 \\
\hline External Test Set & 187 & 7291 & 3.2 & -0.02 & 10.3 \\
\hline All data & $\mathbf{9 1 3}$ & $\mathbf{3 3 1 3 9}$ & $\mathbf{1 . 5}$ & $\mathbf{- 0 . 0 2}$ & $\mathbf{9 . 2}$ \\
\hline \multicolumn{7}{|c|}{ Model 3 (asymmetric, high-pressure systems) } \\
\hline Training Set & 49 & 1944 & 8.8 & 6.5 & 5.8 \\
\hline Validation Set & 16 & 700 & 11.8 & 8.3 & 5.7 \\
\hline Internal Test Set & 6 & 389 & 4.3 & 3.8 & 6.4 \\
\hline External Test Set & 26 & 855 & 7.0 & 5.2 & 7.8 \\
\hline All data & $\mathbf{9 7}$ & $\mathbf{3 8 8 8}$ & $\mathbf{9 . 0}$ & $\mathbf{1 . 2}$ & $\mathbf{6 . 0}$ \\
\hline
\end{tabular}


Table 8. Comparison of Bubble-point Pressure Predictions with Previous Work [15]

\begin{tabular}{|c|c|c|c|c|c|c|c|}
\hline Model & $\begin{array}{l}\text { No. of } \\
\text { Descriptors } \\
\text { (Model } \\
\text { Input) }\end{array}$ & $\begin{array}{c}\text { Descriptor } \\
\text { Type }\end{array}$ & Data set & No. sys. & NDP & RMSE & $\begin{array}{c}\text { \%AAD } \\
\text { in P }\end{array}$ \\
\hline \multirow{3}{*}{$\begin{array}{l}\text { This work } \\
\text { (Model 2) }\end{array}$} & \multirow{3}{*}{10} & \multirow{3}{*}{$\begin{array}{l}\text { Readily } \\
\text { Available } \\
\text { Molecular } \\
\text { Properties }\end{array}$} & $\begin{array}{l}\text { Training } \\
\text { Set }\end{array}$ & 459 & 16570 & 0.3 & 8.4 \\
\hline & & & $\begin{array}{l}\text { External } \\
\text { Test Set }\end{array}$ & 187 & 7291 & 3.2 & 10.3 \\
\hline & & & All data & 913 & 33139 & 1.5 & 9.2 \\
\hline \multirow{3}{*}{$\begin{array}{l}\text { Previous } \\
\text { work [15] }\end{array}$} & \multirow{3}{*}{30} & \multirow{3}{*}{$\begin{array}{l}\text { Molecular- } \\
\text { Structure- } \\
\text { Based } \\
\text { Descriptors }\end{array}$} & $\begin{array}{l}\text { Training } \\
\text { Set }\end{array}$ & 459 & 16570 & 0.2 & 7.3 \\
\hline & & & $\begin{array}{l}\text { External } \\
\text { Test Set }\end{array}$ & 187 & 7291 & 2.7 & 10.1 \\
\hline & & & All data & 913 & 33139 & 1.1 & 8.3 \\
\hline
\end{tabular}




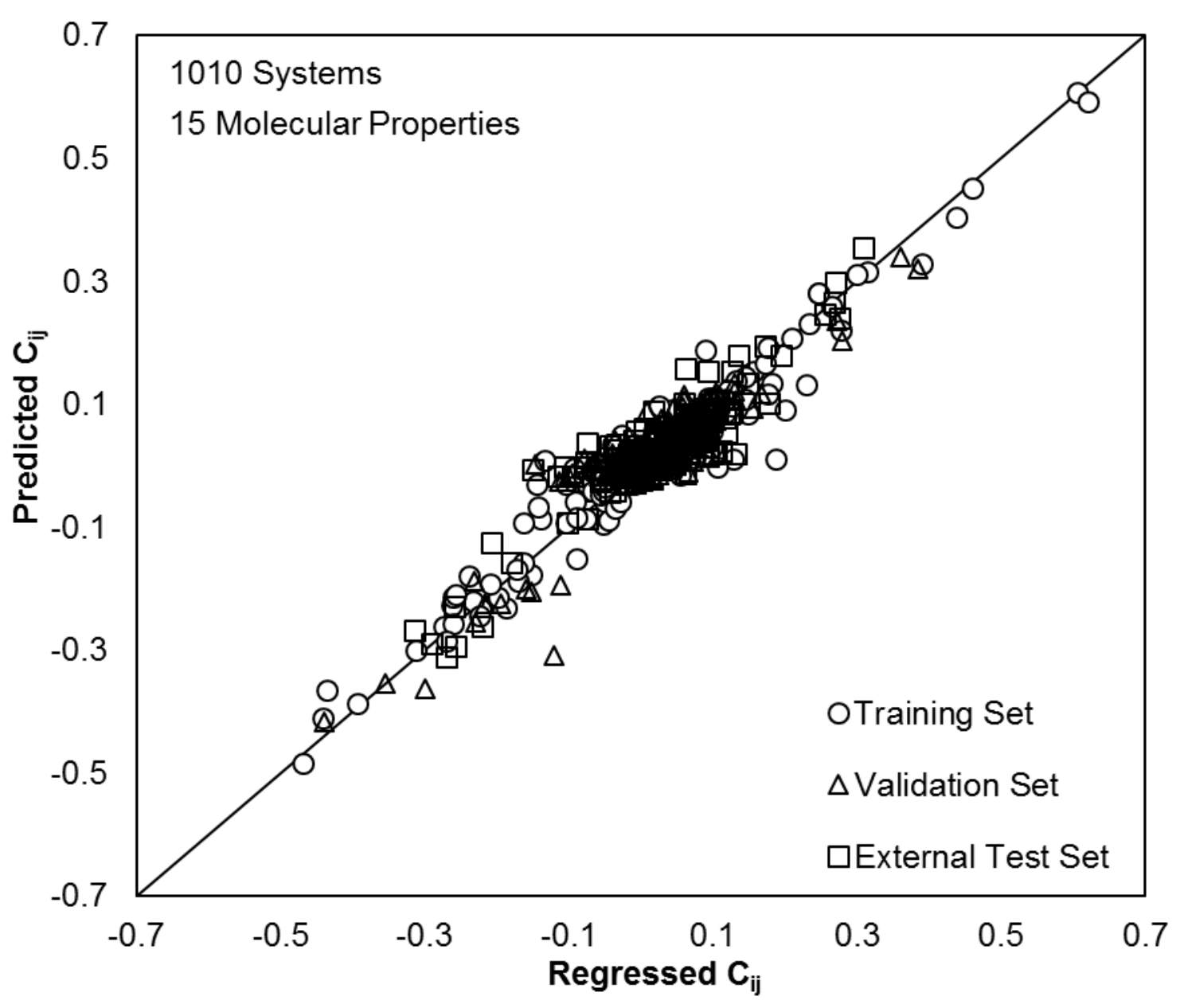

Figure 1. Comparison of the Regressed $C_{i j}$ from PR EOS and Predicted $C_{i j}$ from Generalized Model 1 


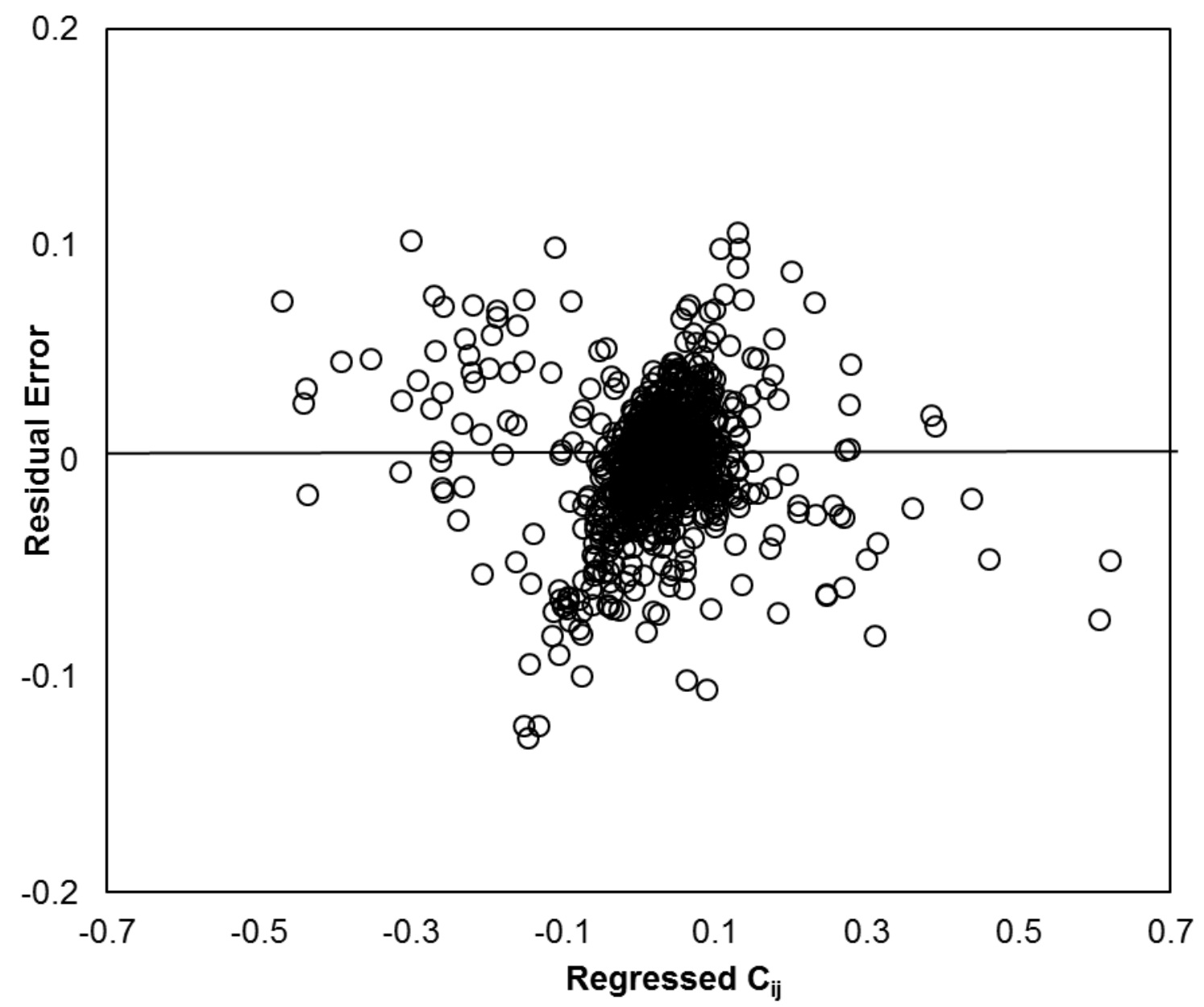

Figure 2. Residuals in $\mathrm{C}_{\mathrm{ij}}$ for Generalized Model 1 


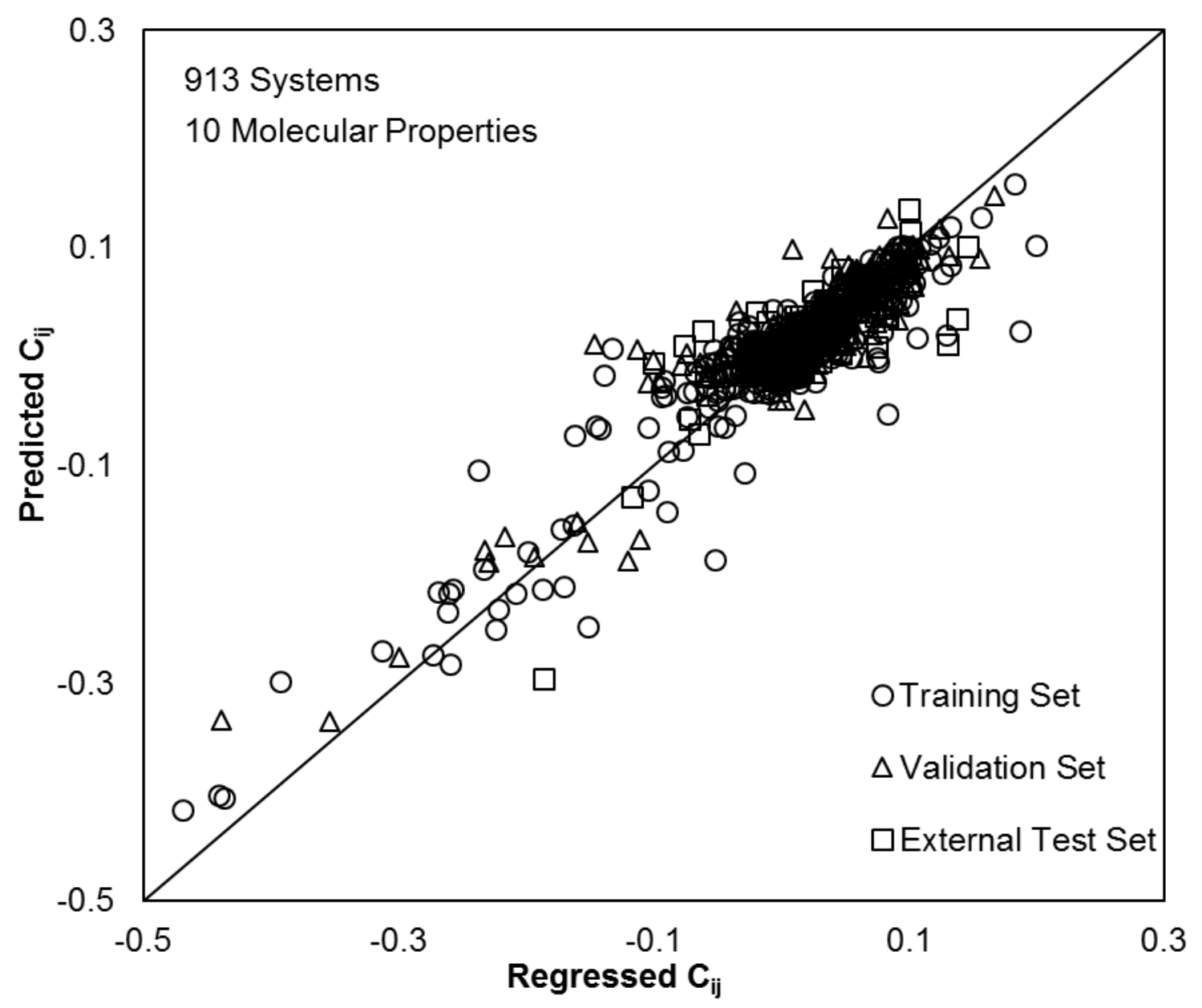

Figure 3. Comparison of the Regressed $C_{i j}$ from PR EOS and Predicted $C_{i j}$ from Generalized Model 2 


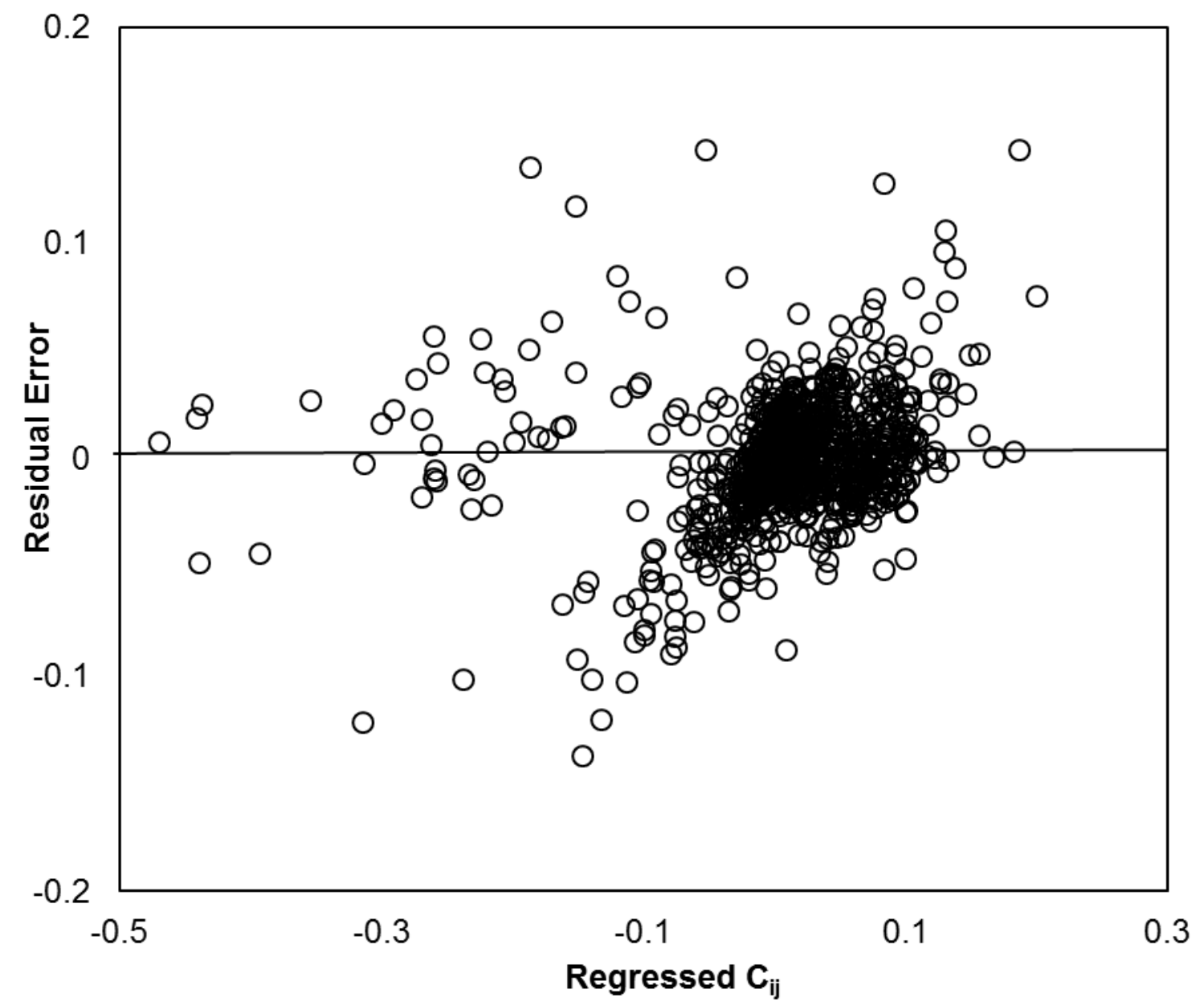

Figure 4. Residuals in $\mathrm{C}_{\mathrm{ij}}$ from Generalized Model 2 


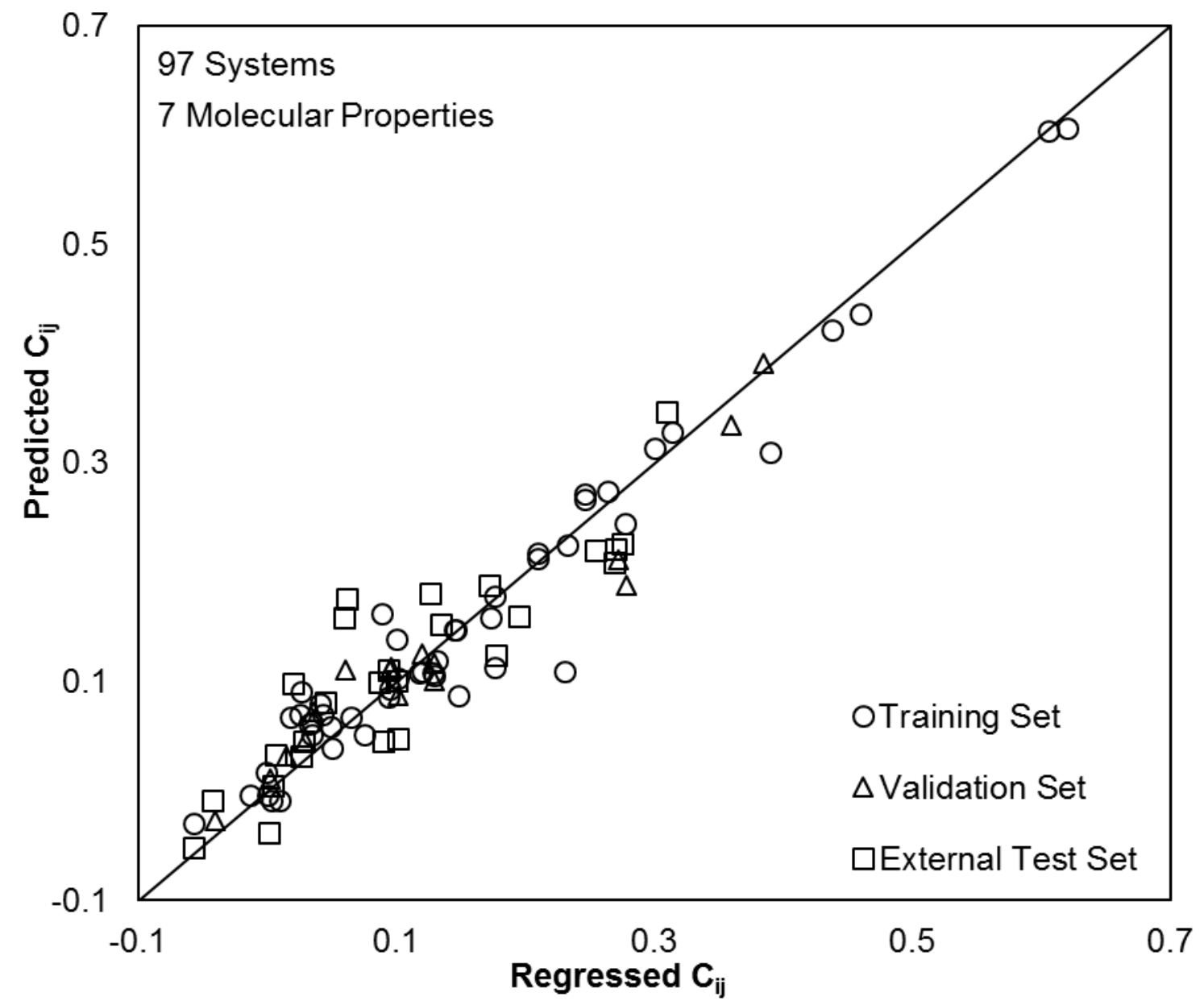

Figure 5. Comparison of the Regressed $C_{i j}$ from PR EOS and Predicted $C_{i j}$ from Generalized Model 3 


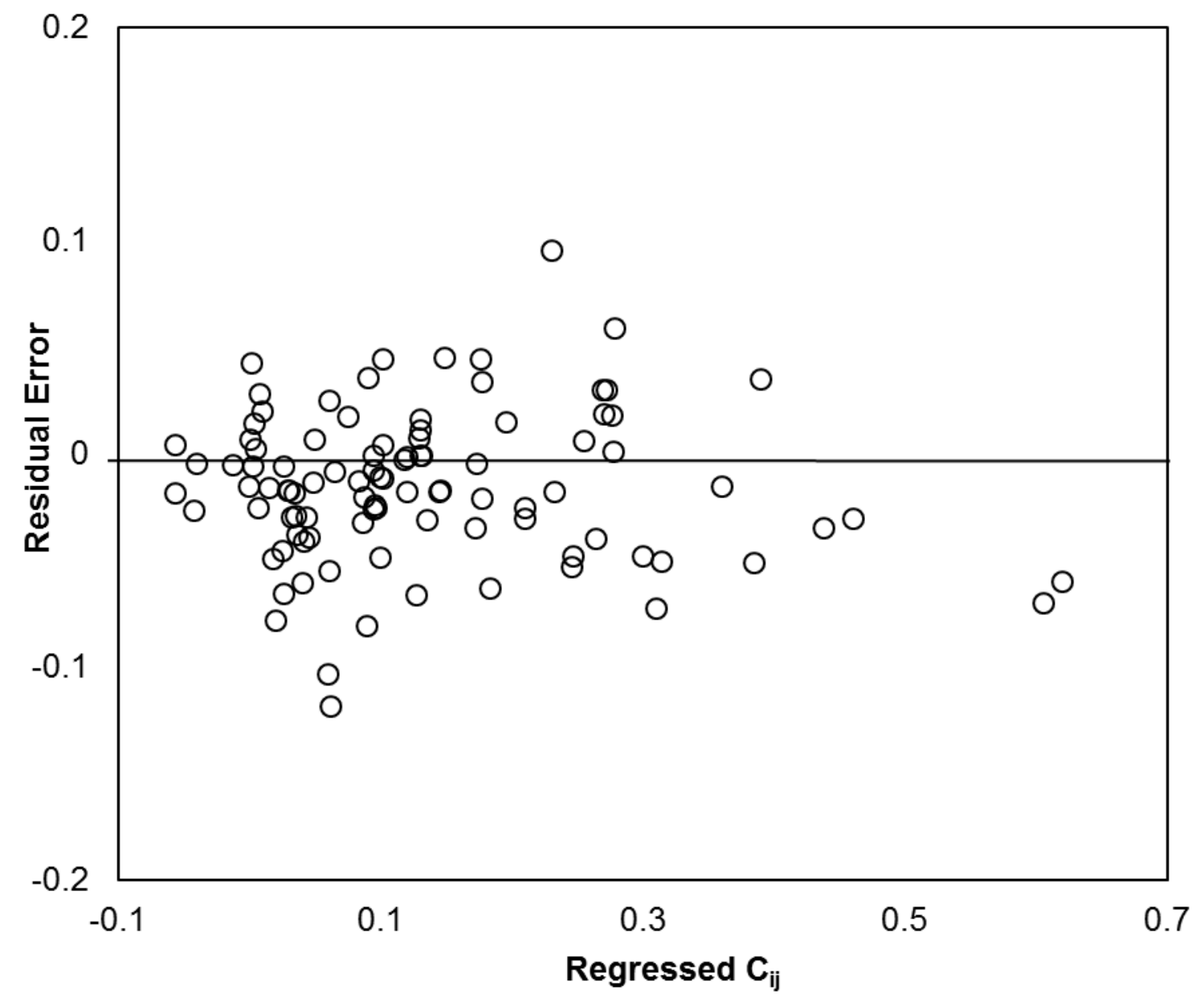

Figure 6. Residuals in $\mathrm{C}_{\mathrm{ij}}$ from Generalized Model 3 


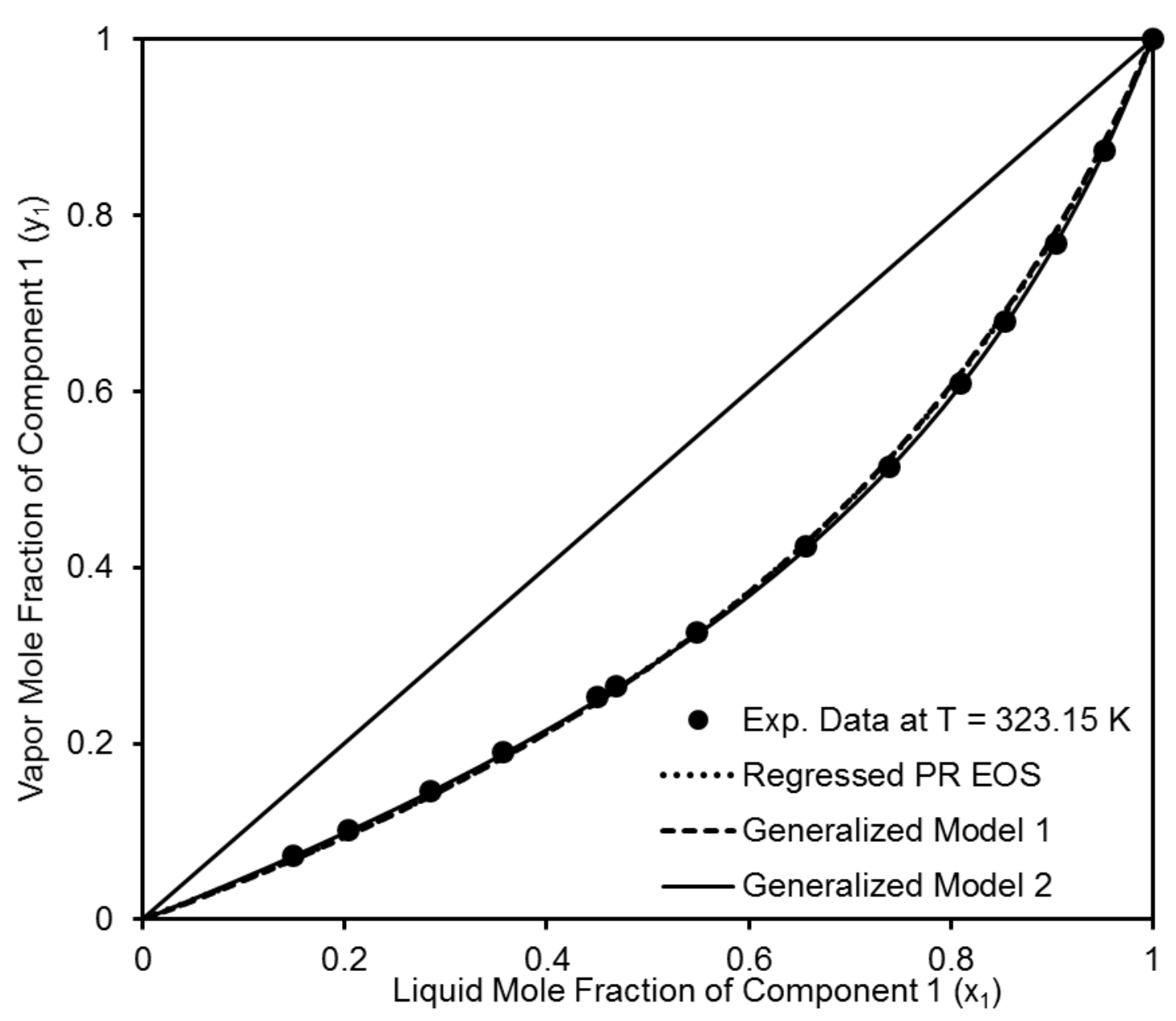

Figure 7. PR EOS Representations and Generalized Model Predictions for Methyl Cyclohexane (1) + Ethyl Tertiary Butyl Ether (2) System 


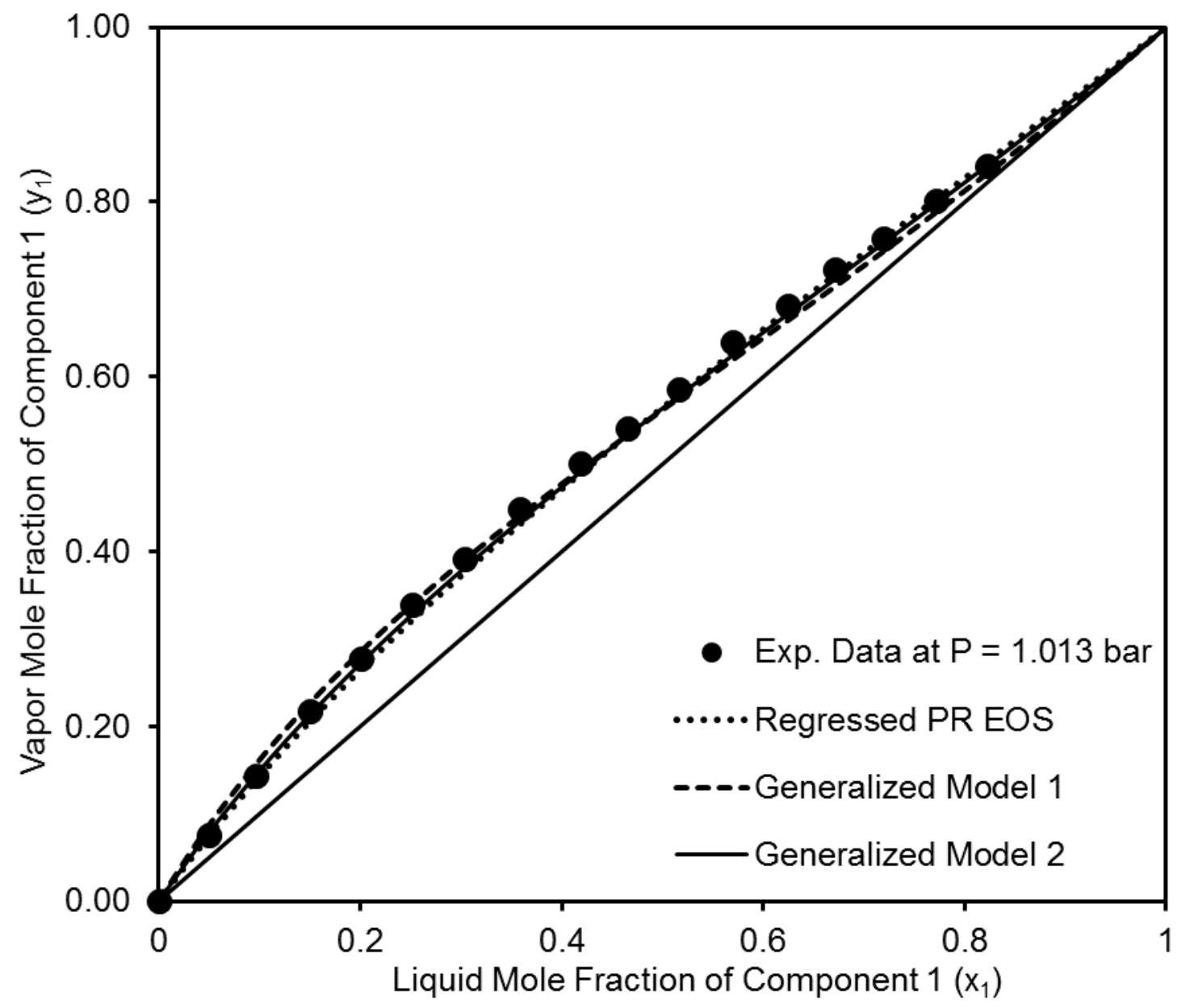

Figure 8. PR EOS Representations and Generalized Model Predictions for n-Octane (1) + Ethylbenzene (2) System 


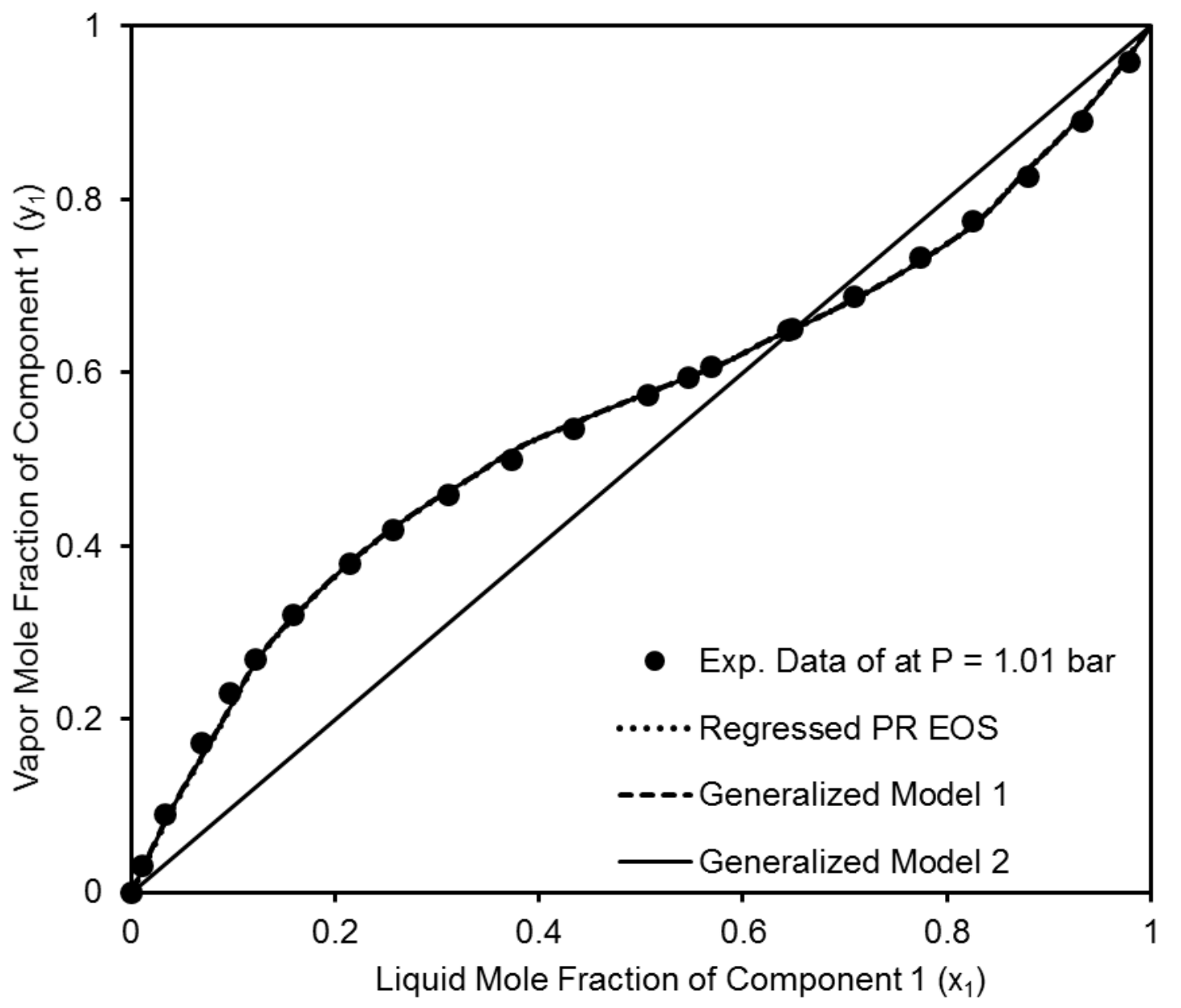

Figure 9. PR EOS Representations and Generalized Model Predictions for Methyl Acetate (1) + Carbon Disulfide (2) System 


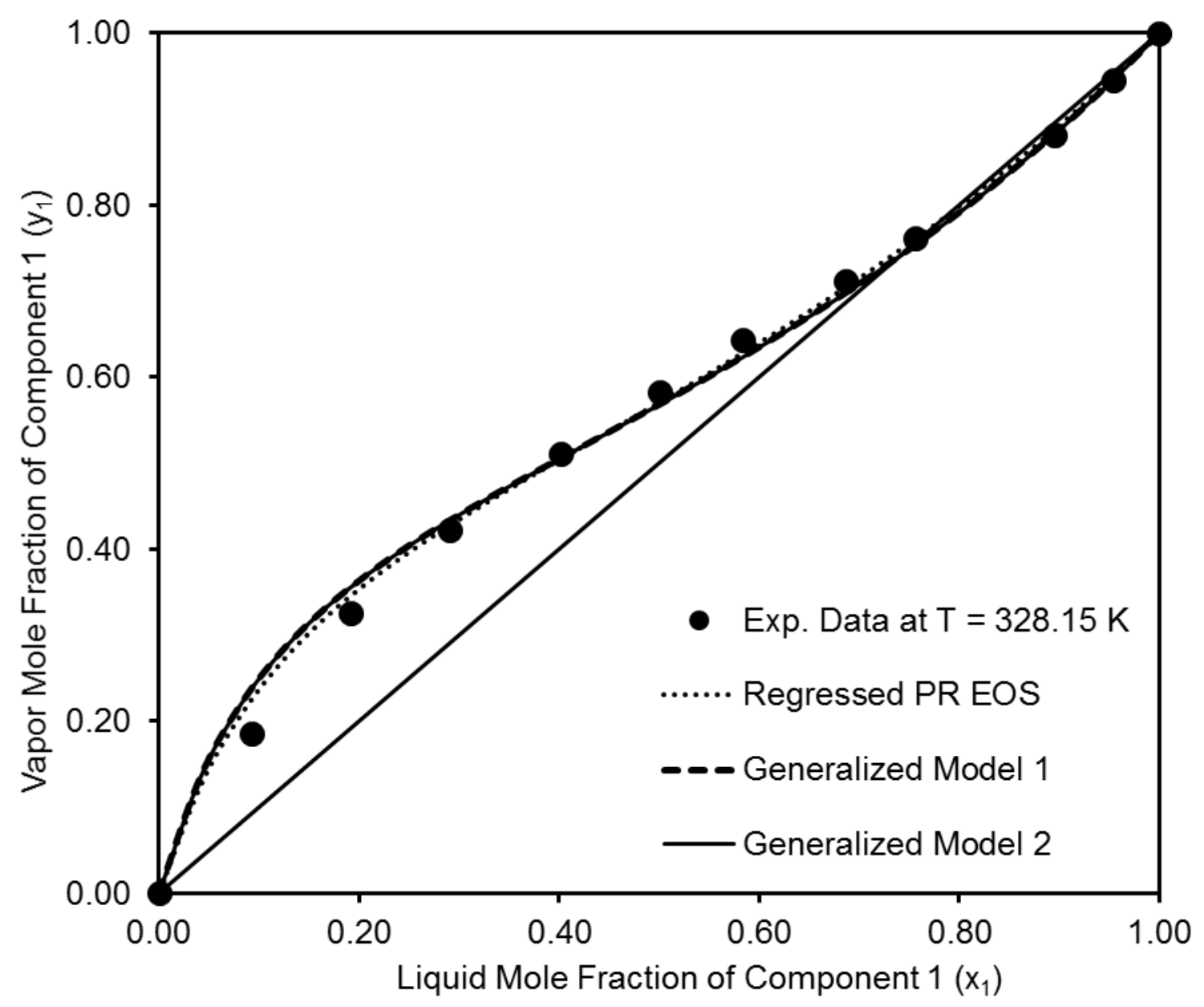

Figure 10. PR EOS Representations and Generalized Model Predictions for Methyl Acetate (1) + Carbon Disulfide (2) System 


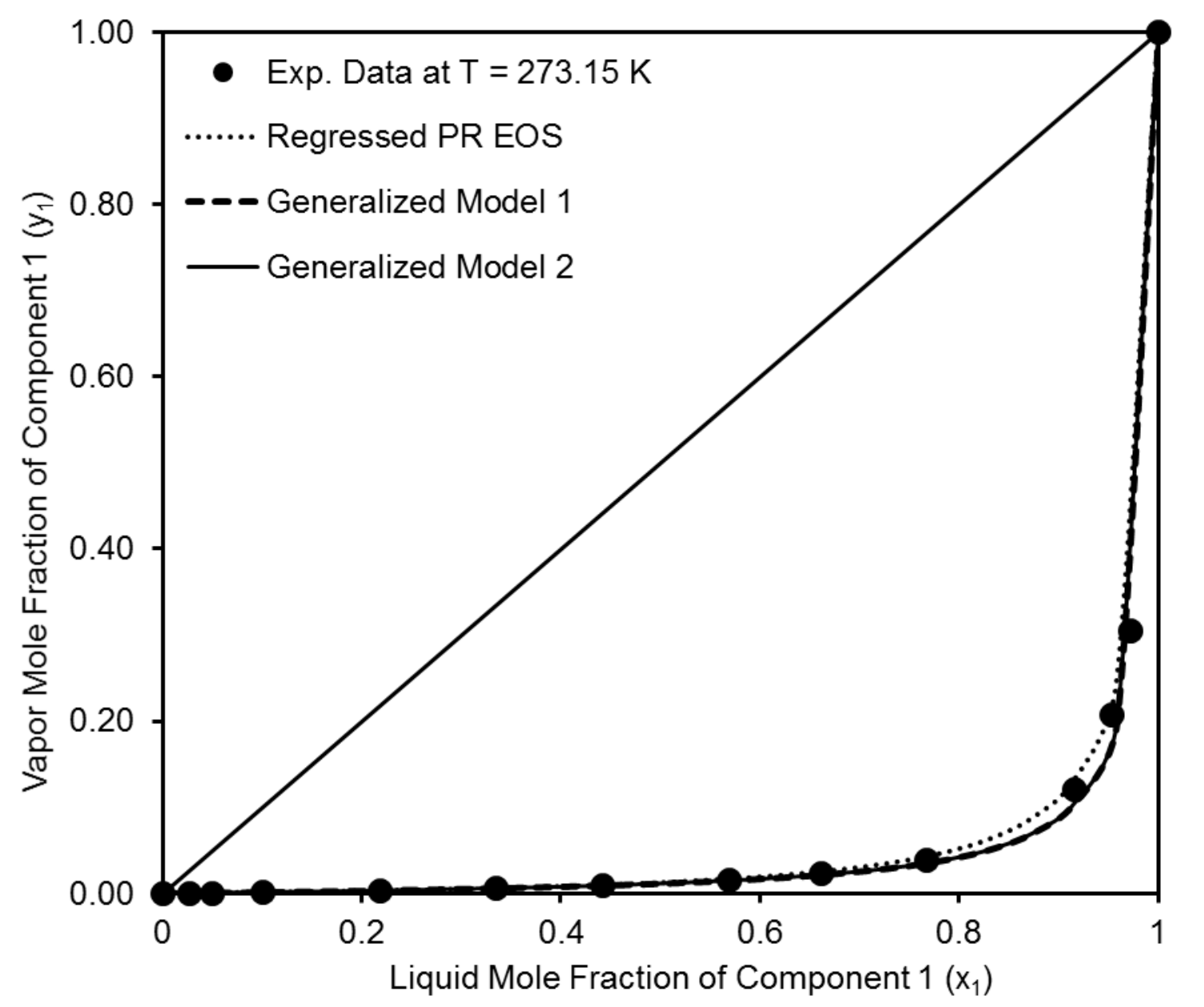

Figure 11. PR EOS Representations and Generalized Model Predictions for Dimethyl Disulfide (1) + Methyl Mercaptan (2) System 


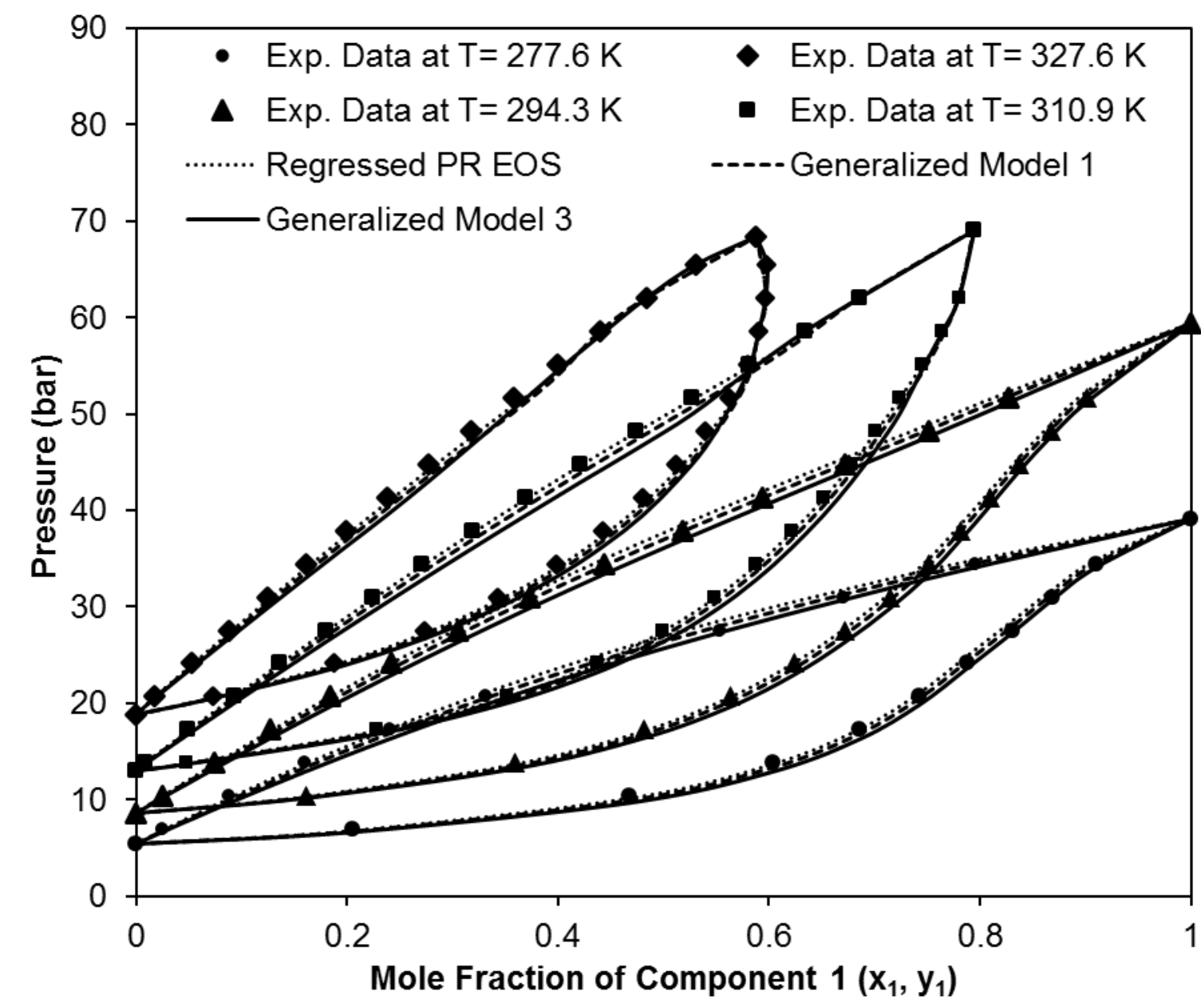

Figure 12. PR EOS Representations and Generalized Model Predictions for Carbon dioxide (1) + Propane (2) System 


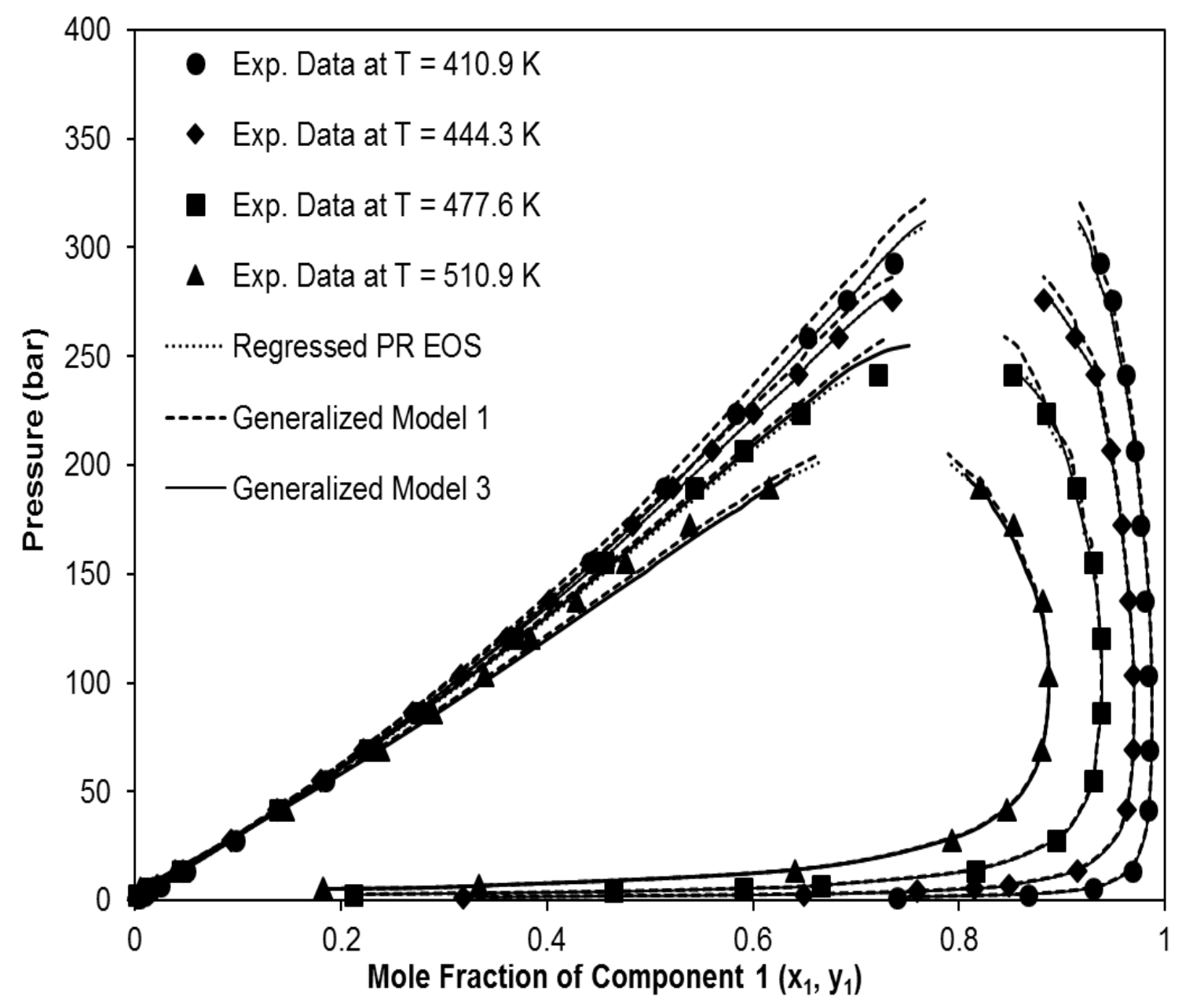

Figure 13. PR EOS Representations and Generalized Model Predictions for Methane (1) + Decane (2) System 


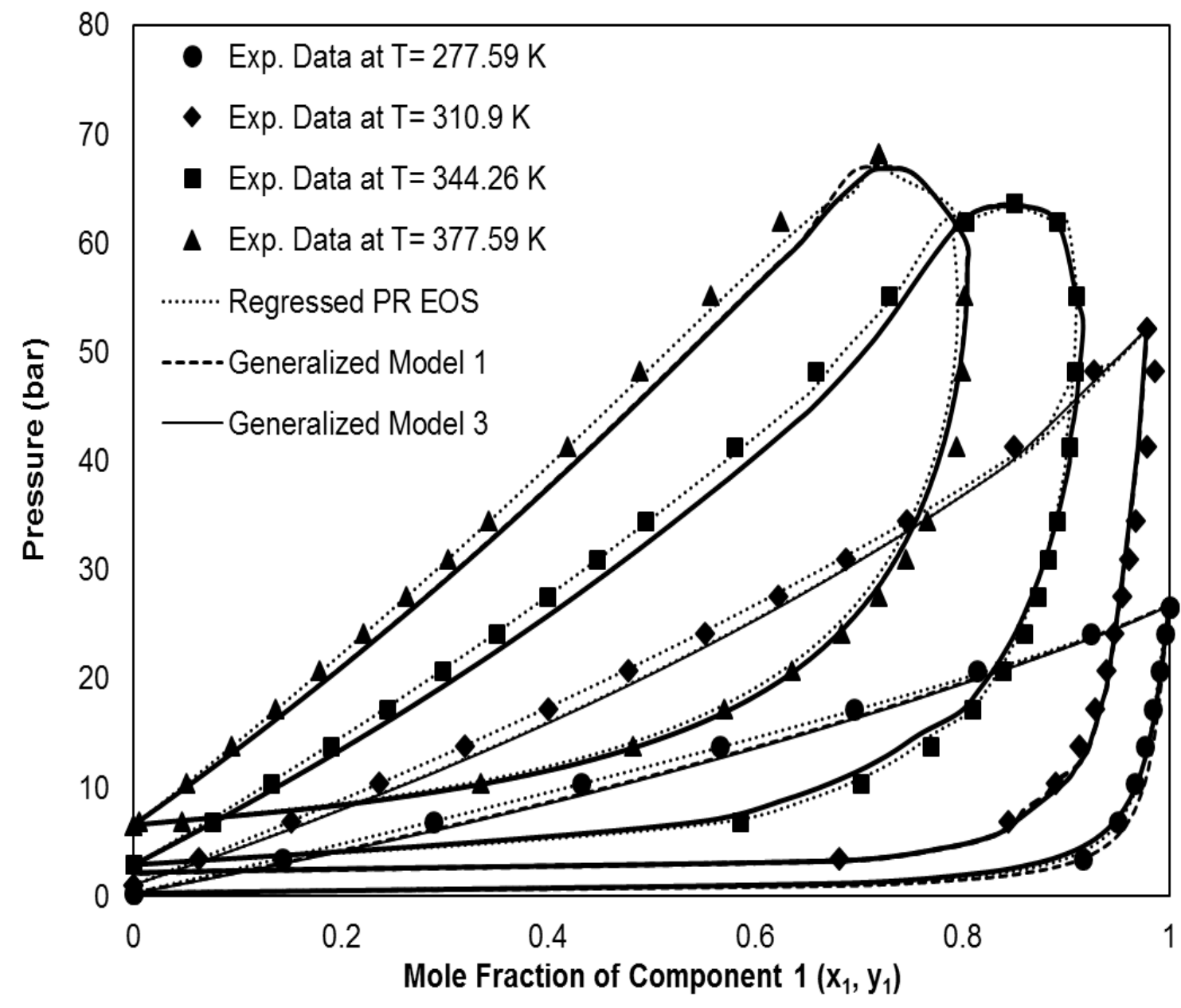

Figure 14. PR EOS Representations and Generalized Model Predictions for Ethane (1) + Pentane (2) System 


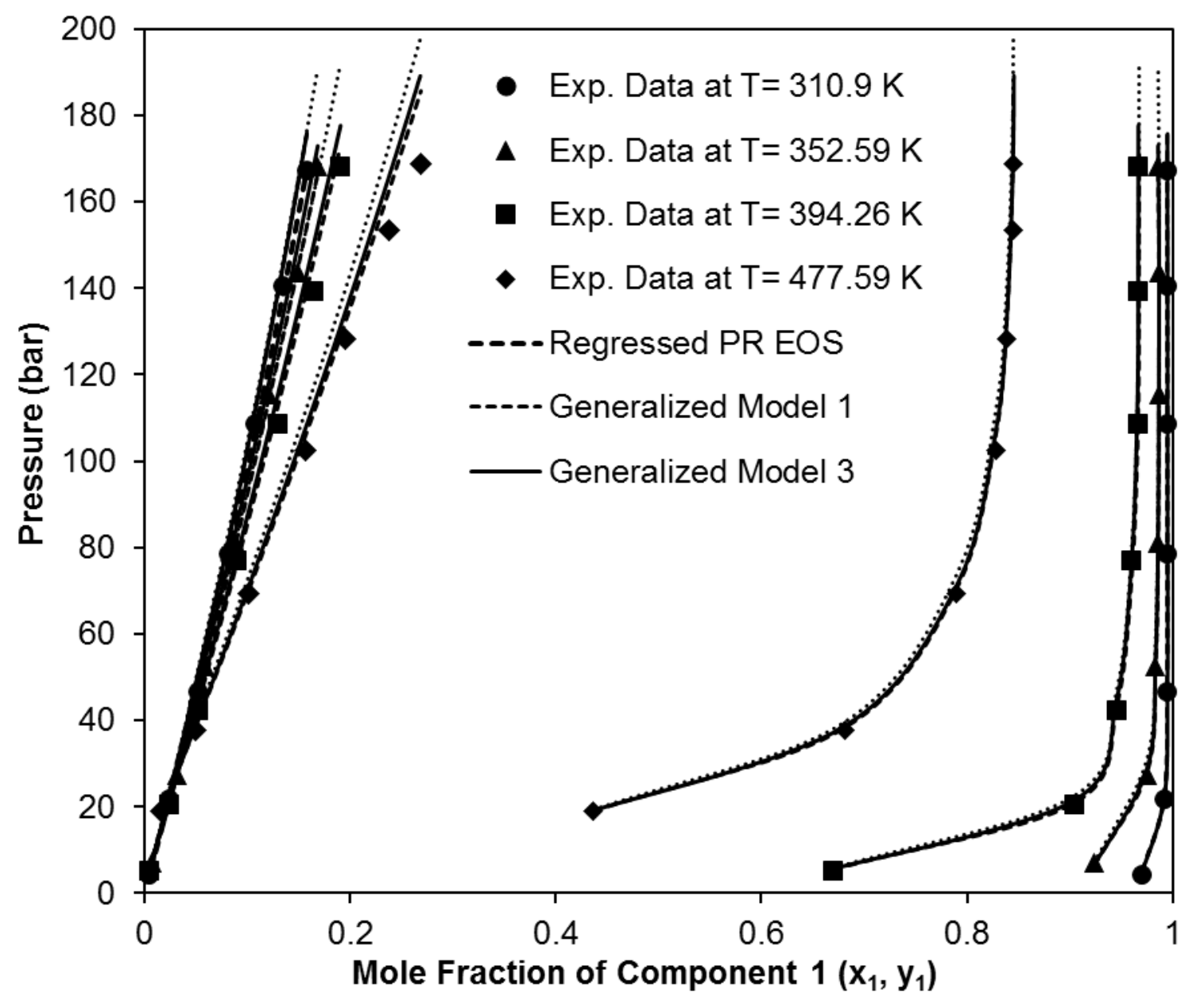

Figure 15. PR EOS Representations and Generalized Model Predictions for Nitrogen (1) + Methylcyclohexane (2) System 


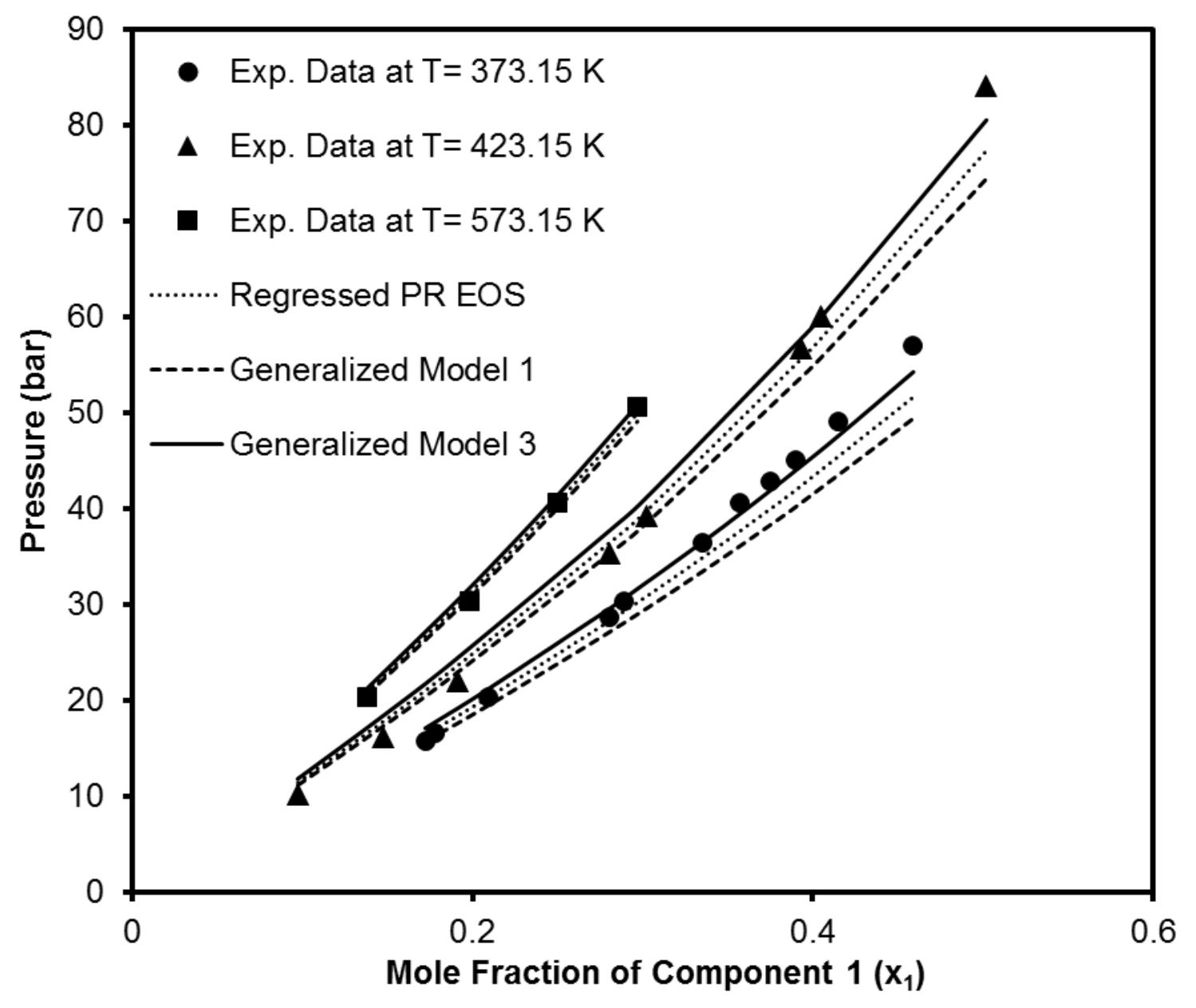

Figure 16. PR EOS Representations and Generalized Model Predictions for Carbon Dioxide (1) + Hexatriacontane (2) System 


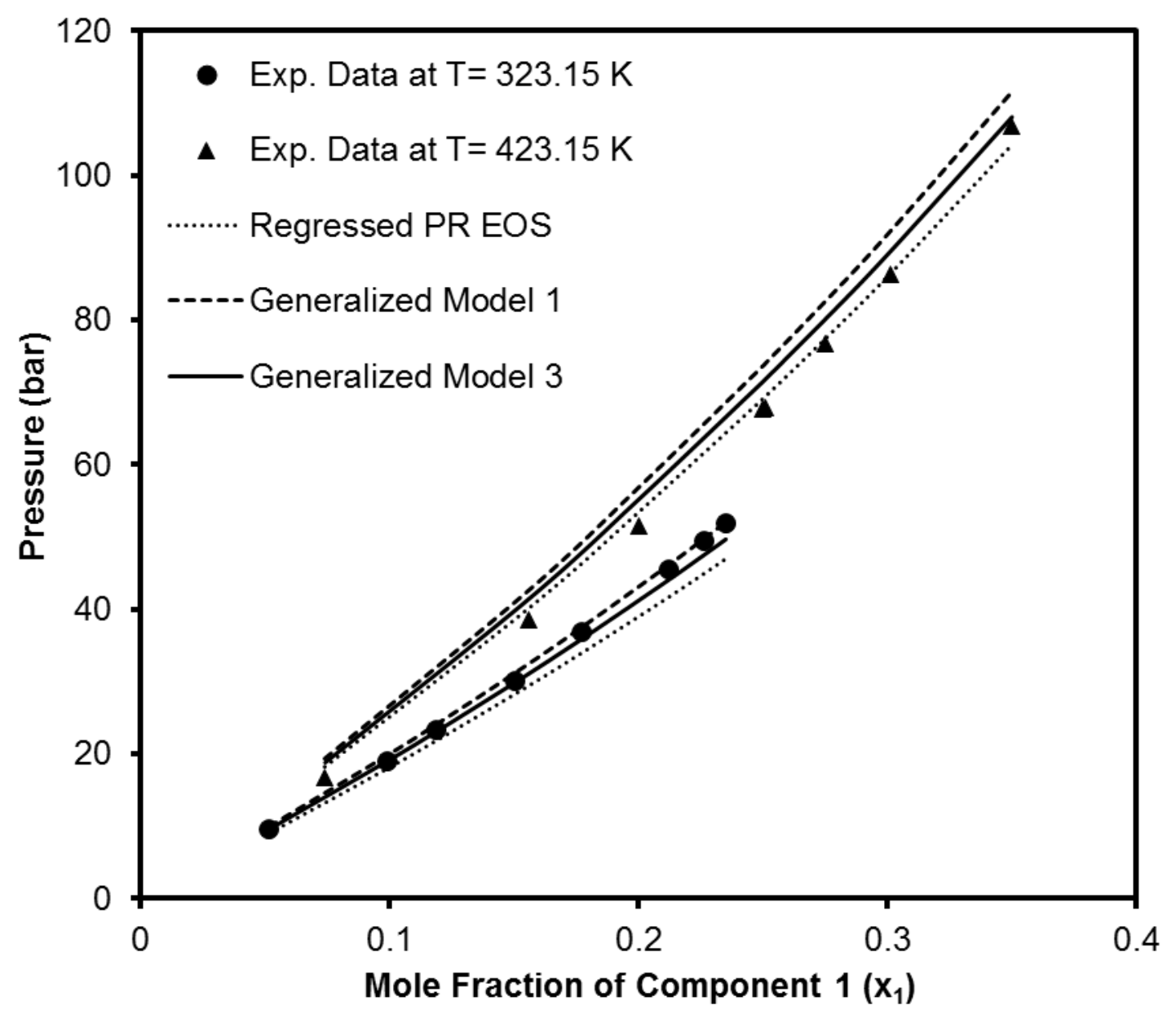

Figure 17. PR EOS Representations and Generalized Model Predictions for Methane (1) + Eicosane (2) System 